\title{
THE BOOK-TO-MARKET AND SIZE EFFECTS IN A GENERAL ASSET PRICING MODEL: EVIDENCE FROM SEVEN NATIONAL MARKETS
}

\author{
Neal Maroney \\ The University of New Orleans \\ School of Business Administration \\ New Orleans, LA. 70148 \\ nmaroney@uno.edu \\ and \\ Aris Protopapadakis \\ University of Southern California \\ The Marshall School of Business, FBE \\ Los Angeles, CA. 90089-1427 \\ aprotopapadakis@marshall.usc.edu
}

First Draft: September 1995

November 22, 1999

\begin{abstract}
We want to thank Bruno Gerard, Tom Goodwin, Alex Huemer, Deborah Sherwood, Craig Stubblebine, Vince Warther, Tom Willett, Paul Zak, participants of the Claremont Graduate School economics seminar and the University of Southern California finance seminar for helpful comments and suggestions. We owe special thanks to Giorgio De Santis for his unstinting help and boundless patience.
\end{abstract}




\begin{abstract}
We find a positive relation between returns and Book-to-Market ratio $(B E / M E)$ and a negative relation between returns and Market Value $(M V E)$ in all the countries we study. The $B E / M E$ and $M V E$ "effects" are international in character and remain strong under a general stochastic pricing function that does not depend on a specific asset pricing model and avoids potentially serious simultaneity biases inherent in the Fama \& French three-factor model. Finally, potentially important macro and financial variables that we add to the pricing functions do not offer an explanation of the $B E / M E$ effect.
\end{abstract}

Applicable JEL Classifications: G10, G12, G15, G30. 


\section{INTRODUCTION}

Several papers show that, in the U.S., stock returns are correlated with the lagged values of their Book-Value to Market-Value ratio $(B E / M E)$ and their market value $(M V E)$, and that average returns are greater the higher the $B E / M E$ or the smaller the $M V E .{ }^{1}$ These anomalous findings are referred to as the "book-to-market effect" and the "size effect"; the $B E / M E$ effect is stronger and more reliable than the $M V E$ effect. $^{2}$ Furthermore, these variables "explain" the average return differences across portfolios that cannot be accounted for by the market portfolio beta (see Fama and French 1992).

Researchers have begun to document that these empirical phenomena are international in scope and not confined to U.S. data, dispelling the suspicion that the $B E / M E$ and $M V E$ effects are due to "data snooping" (see Lo \& MacKinlay 1991, Black 1993, and MacKinlay 1995). Early papers find evidence of a "value growth factor" in some international data. ${ }^{3}$ More recent papers by Fama \& French (1997), Heston, Rouwenhorst \& Wessels (1997), and Rouwenhorst (1998) extend these early findings. They find cross sectional evidence of the $B E / M E$ and $M V E$ effects within several international markets. The tests reported by Fama \& French (1997) Heston, Rouwenhorst $\&$ Wessels (1997) and Rouwenhorst (1998) use a three-factor CAPM variant that includes

\footnotetext{
1 See Banz (1981), Basu (1983), Keim (1983) for the MVE (Size) effect, and Stattman (1980), Fama \& French (1992), and more recently Daniel \& Tittman (1997) for the $B E / M E$ effect. A related but less pronounced empirical regularity exists between a firm's earnings-price, $E / P$ ratio and expected returns. Basu $(1977,1983)$ and Reinganum (1981) document that firms with high $E / P$ ratios have higher average returns than those with low $E / P$ ratios.

2 There have been several but as yet not wholly successful attempts to find a theoretical explanation for this empirical regularity. The most obvious explanation is that $B E / M E$ or $M V E$ proxies for an unobservable risk factor. However, there is no satisfactory theoretical model that makes this connection clear. Ikenberry, Lakonishok, and Vermaelen (1994) relate this behavior of average returns to share repurchase programs; Loughran and Ritter (1994) and Spiess and Affleck-Graves (1994) connect this behavior to the price behavior of IPOs. Fama and French (1995) find links between returns, earnings, and Size and $B E / M E$ factors. An intriguing possibility is advanced by Ferguson and Shockley (1999), that the $B E / M E$ effect is created by the mismeasurement of the market portfolio due to the omission of corporate bonds.

3 Capaul, Rowley, and Sharpe (1993) find a significant "value-growth factor" when they compare the risk-adjusted rates of return from indices composed of value and growth stocks in all five international markets they study (France, Germany, Switzerland, U.K., and Japan). Chan, Hamao, and Lakonishok (1991) find a strong relation between $B E / M E$ and average returns in Japan, using a SUR procedure.
} 
the $H M L$ portfolio as a factor that accounts for the $B E / M E$ effect. ${ }^{4,5}$ These papers report that cross-sectional return differences of portfolios sorted according to $B E / M E$ ratios disappear; furthermore, they report $R^{2}$ close to one. The authors attribute their results to the significance of the $H M L$ portfolio, hence the $B E / M E$ effect.

Tests of the significance of the $B E / M E$ and $M V E$ effects reported to-date suffer from two potentially serious shortcomings. The first is that they use variants of the CAPM to account for systematic risk. ${ }^{6}$ As a result, these tests depend on a specific benchmark model. If the wrong benchmark is chosen, then differences in average returns (or risk premia) may be incorrectly attributed to the existence $B E / M E$ or $M V E$ effects. Evidence that rejects the CAPM is common in the literature, and there is no agreed-upon empirical model to replace it. Therefore, it is extremely important to construct tests that do not rely on any specific asset pricing model.

The second serious shortcoming is that most of the reported tests use OLS methodology. It is at best doubtful that these tests satisfy the OLS requirement that the explanatory variables are independent of the LHS variable, because the tested portfolios constitute a significant portion of the market index, which is the explanatory variable.

In this paper we report results of tests that are free of these shortcomings. We use a very general asset pricing function to investigate the $B E / M E$ and $M V E$ effects in seven national equity markets. This pricing model does not rely on the CAPM or ICAPM, and it encompasses all pricing functions that can be constructed from linear combinations of returns. At the same time, our methodology explicitly takes into account the endogeneity of the various portfolios relative to the market portfolio. Our tests are by country and therefore do not rely on the assumption of international capital market integration.

\footnotetext{
4 The $H M L$ portfolio is an arbitrage portfolio that consists of the difference in returns of the high $B E / M E$ and the low $B E / M E$ portfolios.

5 In a recent paper Ferson, Sergei \& Sarkissian (1999) point out plausible conditions under which this approach gives entirely misleading results.

6 Exceptions are Huberman and Kandel (1987), MacKinlay and Richardson (1991), and Ferson, Foerster, and Keim (1993), who use the Latent Variables model to test if a subset of size-sorted portfolios span a larger set of size-sorted portfolios in the U.S. De Santis (1993) derives the spanning test we use based on the Hansen-Jagannathan methodology. He uses spanning tests to compute gains from international diversification and to assess the role of foreign exchange risk, and De Santis (1994) reports
} 
Our tests of the $B E / M E$ and $M V E$ effects are "spanning" tests that use Stochastic Discount Factors or SDFs. These SDFs are constructed with the methodology proposed by Hansen \& Richard (1987) and Hansen \& Jagannathan (1991). Since they encompass all rational asset pricing models, they impose the fewest restrictions on the ability of asset returns to price risk; they insure only that the Law of One Price is not violated. Spanning tests consist of constructing candidate SDFs from a subset of portfolios (reference portfolios) and using these to price or "span" all the assets in the market. Successful pricing or spanning implies that the SDFs adequately replicate the average returns of all the portfolios. Unconditional SDFs are constructed using only portfolio returns, while conditional SDFs are augmented with lagged values of other variables.

Our results confirm many but not all of the results in the recent literature. The $B E / M E$ and $M V E$ effects survive this very general pricing model for all the countries examined. We find that spanning with the unconditional SDFs is overwhelmingly rejected for all the countries, unless the largest and smallest ranked $B E / M E$ (or $M V E$ ) portfolios are included in the SDF. When they are included, spanning is much more frequent but not universal. This finding supports the procedure of including the $H M L$ portfolio as a "factor" in augmented CAPM models. We formally test the significance of the $B E / M E$ and $M V E$ variables by inserting their lagged values as instruments in the SDFs; the evidence is very strong that either of these variables should be included. We conclude that the Book-to-Market and Size effects are not artifacts of CAPM's shortcomings.

Next we test if the $B E / M E$ - or $M V E$-augmented SDFs (conditional SDFs) span better than the unconditional ones. We find the same pattern as for the unconditional SDFs; the overall spanning performance is not satisfactory.

Finally, we examine if the significance of $B E / M E$ as an instrument in the SDF is robust against 15 plausible macroeconomic and financial variables for each country, and if any of these variables helps improve spanning performance.

We find that the significance of $B E / M E$ is not diminished when we test it against each of these variables. At the same time, some of these new variables help price the 
assets better, together with $B E / M E$. We also find that even when the SDFs are augmented by $B E / M E$ and the 15 macro/financial variables, they do not always span. The additional macro/financial variables improve spanning performance only slightly. Thus, the SDFs we estimate do not account completely for the cross-sectional variation of average returns. This finding is in contrast with the current conclusion in the literature that $B E / M E$ accounts completely for the cross sectional variation in returns, through the $H M L$ portfolio.

We study stock returns for Australia, Canada, Germany, France, Japan, the U.K., and the U.S. These are the only national stock markets in the COMPUSTAT Global Vantage database with a sufficiently large number of equities traded over the sample period to allow us to form at least seven well-diversified, country-specific portfolios for our tests. This database is shorter than that used by Fama \& French (1997) but it includes more stocks for each country.

The pattern of average returns for all our countries is very similar to that of the U.S. Average returns generally increase as the portfolio's $B E / M E$ increases or its $M V E$ decreases. For all our countries, the largest returns accrue to the highest $B E / M E$ and to the smallest $M V E$ portfolios, and there is a flat relation between average returns and portfolio betas for all the countries. Jensen's alphas increase as the $B E / M E$ of the portfolios increases or as their $M V E$ decreases, and the inclusion of an international $H M L$ portfolio (Fama \& French 1997) drives the Jensen's alphas to zero. Sharpe ratio plots also indicate that the risk-to-reward ratio also increases with $B E / M E$ and $M V E .^{7}$

The statistical features of our data and the results of the standard tests are very similar to those reported by researchers that use the IFC or other datasets. This suggests that the new results we present are not dataset-dependent.

Section 2 describes the data used in the study and the construction of the relevant variables and portfolios. Section 3 presents summary statistics for the data and

$B E / M E$.

7 Haugen (1994) examines Sharpe ratios for the U.S. and concludes that low volatility "value stocks" outperform their higher volatility "growth" counterparts over five-year investment horizons. 
replications of existing results, while section 4 presents our new tests. Section 5 offers concluding comments. The appendices contain some technical information. 


\section{DATA}

The firm level equity market data are from COMPUSTAT Global Vantage, compiled by Standard and Poor's Inc. ${ }^{8}$ Data for stock indices, other financial variables, and the macro variables, are obtained from DataStream.

The rest of this section outlines in more detail the data used, the selection of the sample, the portfolio formation process, and the construction of the $B E / M E$ and $M V E$ variables. We discuss the particulars of the macro and other financial variables when they are introduced into our analysis.

\subsection{Equity Market Data:}

The COMPUSTAT database lists firms that, (i) are included in the MSCI World Index, (ii) are included in the MSCI country indices, (iii) are included in the major stock exchange indices of the countries, or, (iv) five or more analysts report on the firm. COMPUSTAT also reports that some shares are included because of direct client requests. For the U.S., the database includes all the NYSE and AMEX stocks, and some of the largest companies in the NASDAQ. This indicates that international COMPUSTAT carries only relatively large firms. Since 1991, firms that have stopped trading, for whatever reason, are retained in the database.

There are potential survivorship biases in the COMPUSTAT data that can erroneously lead to finding a $B E / M E$ effect. Survivorship has been extensively studied in the U.S. data. Kothari, Shanken, \& Sloan (KSS, 1995) and Breen \& Korajczyk (1995) find that if a survivorship bias exists, it is more likely to be found among the smallest firms, most of which are listed on the NASDAQ. The international COMPUSTAT dataset is less likely to have survivorship bias problems, because it contains the relatively larger firms of each country. Thus, it is unlikely that our results are influenced by survivorship bias.

We construct well-diversified portfolios for each country in order to reduce random noise in the returns. Based on the literature and the number of stocks traded in 
the various national markets, we form 7 portfolios for tests that involve one-way sorts, and $9(3 \times 3)$ portfolios for tests that involve two-way sorts. ${ }^{9}$ Therefore, we consider only countries that list a substantial number of stocks. Of the 62 countries represented in COMPUSTAT, only 7 meet this criterion: Australia (AUS), Canada (CAN), Germany (DEU), France (FRA), the U.K. (GBR), Japan (JPN), and the U.S. (USA). Together these countries account for over $80 \%$ of the 7,623 firms included in the dataset. Among these, Germany lists the smallest number of stocks; $167 .{ }^{10}$ We include in our sample only the common stock of private non-financial firms that report accounting figures in the same currency as the nationality of their exchange. ${ }^{11,12}$ The database contains monthly data from January 1982 through October 1994 for the U.S. and Canada, and December 1985 through October 1994 for Australia, Canada, France, Germany, Japan, and the U.K. We exclude October 1987 from all estimation because of the unusual and extreme character of the events related to Black Monday.

The MSCI world index is used to proxy for the world market portfolio.

\subsection{Portfolio Formation:}

Equally-weighted portfolios for each country are formed at the end of each October of year $t$ by sorting stocks by Market Value of Equity (MVE) and Book-to-Market Equity (BE/ME) separately (for one-way sorts), and by sorting first by $M V E$ and then by $B E / M E$ for two-way sorts. For the $M V E$ sorting, the Market Value of

\footnotetext{
8 This seems to be the most complete generally available database that contains the necessary accounting information.

9 It is desirable to keep the number of portfolios small because the reliability of the test statistics we use deteriorate when larger models are tested on small samples.

10 Of the base set of 7,623 firms from 48 countries, a total of 6,401 firms from 7 countries satisfy our criteria, that each firm reports at least 2 prices, 1 shares outstanding figure, and 1 book value for the entire period. The proportion of the selected firms to total firms by country is: USA-42\%, JPN-14\%, GBR-13\%, CAN-6\%, AUS-3\%, FRA-3\%, DEU-2\%.

11 No preferred stock or identifiable issues of subsidiaries are considered.

12 There are a total of 41 firms that have accounting and market information in two different currencies. This occurs mostly with firms incorporated in New Zealand that trade in Australia and Irish firms that trade in the UK. These firms are excluded from the portfolios. In general, cross-listing of the same firm on two national exchanges is not an issue in this dataset. This is because market information is linked with accounting data, and COMPUSTAT reports consolidated balance sheets in the country of incorporation.
} 
Equity for each stock is the product of the year $t$ October price and the number of shares outstanding last reported.

For the $B E / M E$ sorts, the Book Value $(B E)$ is from the balance sheet reported no later than the end of April of year $t$. It includes shareholders' equity plus balance sheet deferred taxes (for Japan deferred taxes are zero). ${ }^{13}$ Book Value is net of goodwill (for Canada, Japan, and U.S. goodwill is zero). For these sortings the Market Equity $(M E)$ is the end of April price (of year $t$ ) times the number of shares last reported. ${ }^{14}$

Portfolios are formed once a year, starting in November of year $t$. To be included in a year $t$ portfolio, firms must have reported an April market value, an April or earlier book value, an October market value, and prices for at least 11 of the 12 following months. ${ }^{15}$ Firms that report negative Book Value are excluded from that year's $B E / M E$ but not the $M V E$ portfolios.

The April deadline for accounting data attempts to minimize look-ahead bias by allowing at least six months to elapse between the time accounting data are recorded and when they are known to the market. ${ }^{16}$ Firms included in any year's portfolios must also have balance sheet data reported as of April of year $t$. If that is not available, it is taken from the prior year. ${ }^{17}$

We construct time series for $(B E / M E)_{i, t}$ and $(M V E)_{i, t}$ for each portfolio ( $i=1$ to 7 [9]). The $(B E / M E)_{i, t}$ variable for the $i^{\text {th }}$ portfolio is the average of the $B E / M E$ s of the stocks included in each portfolio. We use the latest April Book Value (the same value

13 These definitions are consistent with Fama and French (1992).

14 A consequence of these conventions is that, for sorting purposes, $M V E \neq M E$. Share splits are accounted for in the data.

15 Firms that fail to meet the October portfolio criteria are only excluded for that year's portfolios. If there is a missing price (maximum of 1), the missing return is replaced by the prior year's average return for the firm; and if that is unavailable, the firm is excluded. Firms that are delisted in the post-formation period are not subject to the eleven of the twelve month criterion; instead the final price or the final distribution is used. After such a delisting, the affected portfolio is re-weighted to reflect the increased investment to other firms within the portfolio.

16 This is consistent with FF (1992). Financial reports of U.S. firms often are not available to the public until four months after fiscal year-end. The fiscal year in Japan is in March for most firms and accounting information is promptly reported (Chan and Lakonishok, 1991). Thus, the six month reporting lag is conservative for the countries that are analyzed.

17 The maximum reporting lag is 2.5 years for firms with fiscal years ending in May for which data are missing for the prior year but have earlier data. 
used for the portfolio selection process, $B E$ ) but the market value is updated monthly, using the current price and the October number of shares outstanding. The $(M V E)_{i, t}$ variable for each portfolio is the sum of the market values at $t$ of the stocks included in each portfolio, normalized by last month's market value of all stocks. We normalize this variable to avoid using a nonstationary variable as an instrument; this normalization preserves the ordering of the $B E / M E$ portfolios.

Finally, we follow Fama \& French (1997) to construct the international $H M L$ portfolio. We use $30 \%$ of the highest $B E / M E$ stocks from each country for the " $H i$ " portfolio and $30 \%$ of the lowest $B E / M E$ stocks from each country for the " $L o$ " portfolio. Then we subtract the returns of $H i$ from $L o$. In this case, all returns are first converted to U.S.\$s and all portfolios are equally weighted.

\section{SUMMARY STATISTICS AND REPLICATION OF EXISTING RESULTS}

We present descriptive statistics and replications of several existing CAPM-based tests, for the seven countries.

The descriptive statistics show that average portfolio returns increase as $B E / M E$ increases or $M V E$ decreases, for all the countries. The $B E / M E$ effect seems stronger than the $M V E$ effect. Next we present Jensen's alpha tests that use the CAPM; these confirm formally the conclusions from the descriptive statistics: The CAPM "beta" does not account for cross sectional differences in average returns. Finally we replicate the Fama \& French tests with the international $H M L$ portfolio and confirm that their results hold in our data as well. Adding the international $H M L$ portfolio to an international CAPM model significantly improves the cross-sectional fit of average returns.

The results in this section are fully consistent with those in the literature, even though we use a somewhat different dataset. This agreement implies that the results of our new tests are unlikely to be dataset-dependent.

\subsection{Descriptive Statistics:}

This section presents important summary statistics for $B E / M E$ - and $M V E$-sorted portfolios for the 7 countries in the sample. Table 1, Panel A shows statistics for the 
portfolios sorted on $B E / M E$, while Panel B shows the same statistics for the portfolios sorted on $M V E$.

For the $B E / M E$-sorted portfolios there is a wide range of $B E / M E$ ratios for each country. The range across the countries is similar; Canada, Germany and the U.K. have the widest range and Japan has the narrowest. The associated MVEs have a relatively narrow range. Generally, the $M V E$ and the $B E / M E$ of the portfolios are negatively related for each country.

For the $M V E$-sorted portfolios, $M V E$ has a very wide but dissimilar range across countries. The ratio of largest-to-smallest $M V E$ varies from a high of 478 for the U.S. to a low of 45 for Japan. ${ }^{18}$ Furthermore, the smallest MVE portfolio is in the U.S.; Japan and Germany have much larger MVEs both for the smallest and the largest portfolios.

Figures $1 \mathrm{~A}$ and $1 \mathrm{~B}$ plot the cross-section of average returns for $B E / M E$ - and $M V E$-sorted portfolios respectively (the data are in Table 1). All the returns are annualized. Table 2 Panel A reports rank correlation coefficients between the portfolios ranked by $B E / M E$ or $M V E$ and their average returns. These confirm the impressions from the figures.

The returns of the $B E / M E$-sorted portfolios generally increase with the $B E / M E$ ratio; the highest $B E / M E$ ratio portfolios have the highest returns, for every country. For all but the U.K., the returns to the largest $B E / M E$ portfolios are much larger than the returns to any of the preceding ones. Furthermore, for all but Germany, the lowest $B E / M E$ ratio portfolios have the lowest average returns. Returns are again strictly monotonic only for Japan ${ }^{19}$.

For all the countries, the smallest $M V E$ portfolios have the highest returns. However, this relation is strictly monotonic only for Japan. Canada, France, and the U.K. have rank correlation coefficients that exceed 0.50 ; the lowest correlation is 0.18 for Australia. Somewhat surprisingly, the correlation for the U.S. is only 0.39 .

The $B E / M E$ ratio appears to have a stronger relation to average returns than $M V E$. Average returns are more highly correlated with the $B E / M E$ rankings (the lowest

18 The next largest ratios are for Canada and the U.K., at approximately 130. These values are in US\$s. 
correlation is 0.64 ) than the $M V E$ ones. This conclusion is consistent with results in the literature for the U.S. (see Fama \& French, 1992).

It is well known that for the U.S. data traditional measures of systematic risk do not explain the relation of returns to the $B E / M E$ - and $M V E$-sorted portfolios. To examine if this holds for all the countries in our sample, we plot the sorted portfolio returns against two traditional measures of risk: The betas with respect to the World Market portfolio and the Sharpe ratios (in Figures 2A, 2B and Figures 3A, 3B, respectively, and Table 1). ${ }^{20}$

There is no clear relation between market betas and average returns across the ranked portfolios. The relation is either flat or has the wrong sign. There is no country for which the highest $B E / M E$ (or lowest $M V E$ ) portfolio also has the highest beta! Furthermore, the relation between the ranked portfolios and the Sharpe ratios look remarkably like those for average returns. The largest $B E / M E$ and the smallest $M V E$ portfolios have the highest Sharpe ratios. These findings imply that the relation of returns to the $B E / M E$ and $M V E$ rankings is not explained well by standard risk adjustments like the market betas or the standard deviations of the returns, for any of the countries in the sample.

The descriptive statistics discussed above broadly confirm that the empirical regularities observed in the U.S. also exist in the other six countries. Furthermore, standard risk adjustments do not seem to account for these regularities for any of the countries. Finally, two-way sorts suggest that the information contained in $B E / M E$ is not duplicated by the $M V E$ variable. ${ }^{21}$

19 Chan, Hamao, and Lakonishok [1991] also find a strong relation for Japan.

20 The Sharpe ratio is a simple but general adjustment for risk: It is the ratio of the average excess returns and their standard deviation. Since these portfolios are highly diversified in the context of the respective national markets, their standard deviations are likely to be good approximations of traditional measures of systematic risk. Some of the Sharpe ratios are negative and their levels are lower than those in figures $1 \mathrm{~A}$ and $\mathrm{B}$ because they are calculated from excess returns.

${ }^{21}$ Fama \& French (1992) show that the BE/ME ratio does better than $M V E$ in explaining the crosssection of returns, for the U.S. data. For that reason we also examine two-way sorts. We sort equities first by $M V E$ and then by $B E / M E$. If $M V E$ contained all the relevant information then the average returns would not be related to $B E / M E$. Plots of average returns reveal that the relation between $B E / M E$ and returns remains within each $M V E$ portfolio. The relation seems most evident in the smallest $M V E$ portfolios, and least evident in the largest $M V E$ portfolios. We include these two-way sorted portfolios in all the analysis. 
The next section shows the results of CAPM-based regression tests that explore the statistical significance of the relations discussed above. For each country, we estimate Jensen's alphas (excess returns) for each portfolio by regressing adjusted portfolio returns on world and local market indices. Then we examine the excess return estimates for apparent regularities. We also replicate recent results reported by Fama \& French (1997) using an international $H M L$ portfolio.

\subsection{CAPM-Based Regression Tests:}

We estimate the following SURE regression model for the two sets of 7 portfolios from one-way sorts (by $B E / M E$ and $M V E$ ) and the 9 portfolios from the two-way sorts (by $M V E$ and then by $B E / M E$ ), for each country separately:

$$
R_{i, t}^{x}=\alpha_{0}+\alpha_{i}+\beta_{m, i} R_{m, t}^{x}+\beta_{w, i} R_{w, t}^{x}+\varepsilon_{i, t} ; \quad i=1,7(9), \quad \alpha_{1} \equiv 0 .
$$

The variables $R_{i, t}^{x}, R_{m, t}^{x}$, and $R_{w, t}^{x}$ are, respectively, local currency returns for the sorted portfolios, the MSCI national market returns, and the World market returns, all adjusted by the local risk-free rate. ${ }^{22}$ The sum, $\alpha_{0}+\alpha_{i}$, is Jensen's alpha (or excess return or zerobeta return) for each portfolio.

Table 2 Panel B shows the rank correlation coefficients between the Jensen's alphas for each set of portfolios and their ranking by $B E / M E$ and $M V E$. High correlations imply that the $B E / M E$ or the $M V E$ effect exists. The table also reports p-values for Wald tests that the zero-beta returns are equal across the portfolios. Detailed results are in Appendix A.

Panel B clearly demonstrates that there are strong positive correlations between zero-beta returns and $B E / M E$ in all the countries. All the rank correlations are high, and the Wald tests are highly significant, except for Germany. The results for the $M V E$-sorted portfolios are considerably weaker. The hypothesis that the zero-beta returns are the same

\footnotetext{
22 The world market portfolio is the MSCI World Index. The returns are translated to local currency returns by the month-end exchange rate. To calculate excess returns we subtract from the returns the following short term interest rates for each country: AUS --average rate on money market; CAN --1 month T-Bill rate; FRA --call money rate; DEU --call money rate; GBR --1 month T-Bill rate; JPN --call money rate; USA --1 month T-Bill rate. All returns are annualized.
} 
across portfolios is rejected only for Canada and the U.S. However, the rank correlations are not much lower for the $M V E$-sorted than the $B E / M E$-sorted portfolios.

These tests quantify and formalize the conclusions from the descriptive statistics. The $B E / M E$ "effect" is found in all the countries in our sample, in unconditional or CAPM-based tests, while evidence on the $M V E$ effect is weaker. These tests do not assume international capital market integration.

\subsection{Tests with a HML Portfolio:}

A somewhat different test has been reported in Fama \& French (1997). They construct an international $H M L$ portfolio as a factor that represents the $B E / M E$ effect. They assume that international capital markets are integrated, and they regress international portfolios --sorted on $B E / M E$-- on the market and the $H M L$ portfolio. They

find that the Jensen's alphas are no longer significantly different from zero, and the alphas do not increase as $B E / M E$ increases.

In Table 2C we report similar results for our data. The table reports the Jensen's alphas $\left(\alpha_{i}\right)$ estimated from regressions (1b) and (1c), below:

$$
\begin{aligned}
& R_{i, t}^{x}=\alpha_{0}+\alpha_{i}+\beta_{w, i} R_{w, t}^{x}+\varepsilon_{i, t}, \\
& R_{i, t}^{x}=\alpha_{0}+\alpha_{i}+\beta_{w, i} R_{w, t}^{x}+\beta_{H M L, i} R_{H M L, t}^{x}+\varepsilon_{i, t} ; i=1,7, \quad \alpha_{1} \equiv 0,
\end{aligned}
$$

where $R_{H M L, t}^{x}$ is the $H i$ minus Lo portfolio returns, and all other variables are as defined for equation (1a). The results clearly show again that the Jensen's alphas estimated from these world portfolios also increase as $B E / M E$ increases and as $M V E$ decreases.

Furthermore, when the HML portfolio is added to the regressions, Jensen's alphas are no longer significant and they have no clear pattern.

As we have discussed already, all the above tests use the CAPM as the benchmark model. It is entirely possible that a more general pricing model would account for the apparent pricing anomalies. Indeed, since the $H M L$ portfolio is constructed from linear combinations of returns, it is reasonable to suspect that such a model could be found.

Furthermore, all these tests share a common difficulty: The LHS portfolios are a significant portion of the market, which is on the RHS; thus the LHS and RHS portfolio 
returns are determined simultaneously. But since classical regression assumptions require at least that the RHS variables are predetermined, it is not clear to what extent one can rely on the coefficient estimates and the associated test statistics.

\section{SPANNING TESTS}

In this section we discuss and implement a set of spanning tests based on the Hansen-Jagannathan --HJ (1991)-- Stochastic Discount Factor (SDF) methodology. The type of test that we use was first proposed by De Santis (1993), and it relies on the idea that one can construct a pricing function (or a stochastic discount factor, SDF) from the returns of portfolios that are traded (or could be traded) in the asset markets. These tests do not depend on the validity of any particular asset-pricing model, so that all linear combinations of the underlying asset returns are potential pricing models; all existing linear models are special cases. A technical description of the construction and properties of a SDF is in Appendix B.

If there is a small number of risk factors in the economy, then a subset of portfolios will price themselves and the remaining assets. If such a subset of assets (reference assets) price or span all the assets (reference and test assets), then the reference assets contain all the necessary pricing information. ${ }^{23}$ This is generally referred to as the unconditional spanning hypothesis (see Huberman \& Kandel, 1987); it is labeled "unconditional" because only the portfolio returns enter the SDF.

The test answers the question: Does the constrained unconditional SDF (from only reference assets) adequately price (i.e., adequately reproduce the average returns) all the portfolios in the market. If it does, then no other information or variable is required to fit average returns. If it does not, then one may augment the SDF with additional "conditioning" variables to see if spanning can be achieved. The statistic generally used for this test is the Hansen J-statistic, a goodness of fit measure.

Technically, the test evaluates the distance between two bounds in returns-variance space (HJ bounds); one bound is constructed from SDFs that include both the reference

23 For example, in the CAPM framework, any two risky frontier portfolios span all the other risky assets. 
and the test assets and the other from SDFs that include only the reference assets. ${ }^{24}$ If the two bounds are sufficiently close to each other we conclude that the reference assets span or price the test assets.

We perform the tests on 7 portfolios sorted by $M V E, 7$ portfolios sorted by $B E / M E$, and 9 portfolios obtained from two-way sorts (by $M V E$ and then by $B E / M E$ ), for each country. We designate 5 out of 7 (or 7 out of 9) portfolios as reference assets and the remaining 2 as test assets. We show in section 4.1, below, that these unconditional SDFs generally do not span the assets. In particular, when portfolios with extreme values of $B E / M E$ or $M V E$ are excluded from the SDFs, spanning is overwhelmingly rejected. But even with the extreme portfolios in the SDFs, spanning is rejected much more frequently than would be expected at random. In the first part of section 4.2 we test the statistical significance $B E / M E$ and $M V E$, one at a time, by including them in the SDFs. They are uniformly significant across all countries. From these two findings we conclude that the $B E / M E$ and $M V E$ "effects" exists in all the countries in our sample, even in the context of our very general pricing model.

In section 4.2 we also test if "conditional" SDFs, augmented with the lagged values of $B E / M E$ or $M V E$ span better than the unconditional SFDs. ${ }^{25}$ We find that there is no improvement in spanning performance.

We continue the investigation in section 4.3 by testing if $B E / M E$ simply proxies for other macro or financial variables, and if substituting or adding such variables can improve spanning performance. We study the marginal value of adding each of 15 macro and financial variables to the SDF, one at a time, along with $B E / M E$. The tests of these additional conditioning variables proceed in the same manner as before. None of these

\footnotetext{
24 The bounds are described by an SDF as the risk-free rate varies. Because the bounds are quadratic, only 2 points on each frontier need to be evaluated to assess if the bounds coincide or not. The so-called "intersection" hypothesis relies on only one point on the frontier, and examines possible intersections of the bounds.

25 Such SDFs are formally equivalent to SDFs constructed only from portfolio returns but with nonlinear coefficients, where the nonlinearity is modeled with the conditioning variables. Empirical evidence shows that time-varying betas and risk premia fit U.S. equity market returns significantly better (Campbell, 1987; Harvey, 1989, 1991; Shanken, 1990). Ferson \& Harvey (1993) find the lagged MSCI world index to be the most important predictor of international equity market returns. Jagannathan \& Wang (1994)
} 
additional variables substitutes for $B E / M E$ but many of them are significant along with $B E / M E$. However, once again conditional SDFs augmented by $B E / M E$ and these new variables, one at a time, produce only minor improvement in spanning performance.

We use the Generalized Method of Moments (GMM, Hansen, 1982) because it is particularly well suited for such spanning tests. ${ }^{26}$ It does not require strong distributional assumptions and it makes it easy to impose orthogonality conditions and overidentifying restrictions. ${ }^{27}$ Furthermore it accommodates the endogeneity of the reference assets because it is not necessary to assume orthogonality between the asset returns on the LHS and the test assets on the RHS. The properties of GMM as it applies to our tests are outlined in Appendix C.

\subsection{Unconditional Spanning:}

Consider constructing an SDF, $S D F($ ref), only from the reference assets. The unconditional spanning test consists of testing if the reference portfolios span all the portfolios. The null hypothesis is that the reference portfolios should price or span all the portfolios adequately. If the null is not rejected, then the portfolios are priced adequately within statistical tolerance, and we can conclude that no $B E / M E$, or $M V E$ exists within the limit of the test's power. If $S D F(r e f)$ fails to price (reproduce the average returns) the assets adequately then we say that unconditional spanning is rejected. This implies that the information carried by the reference assets is not sufficient to price all the assets, and that additional information may be needed.

\section{1.a Test Specification:}

We estimate SDFs that maximize the fit across all 7 (9) portfolios while restricting the weights of the test portfolios in the SDF to be zero. For the $B E / M E$ - and $M V E$-sorted

\footnotetext{
find that the importance of $M V E$ is greatly reduced when they allow for time variation in market betas over the business cycle, in addition to their human capital variable.

26 GMM is a convenient method that is generally used to impose the condition that the pricing errors of the SDFs should be orthogonal to $Z_{s, t-1}$.

27 This generality is very useful because the HJ bounds assume little more than finite first and second moments for asset returns.
} 
portfolios, we designate 5 of the 7 portfolios as reference assets and the remaining 2 as test assets. For the two-way sorted portfolios we designate 7 as reference and 2 as test assets. We report results for different combinations of test assets.

Let the first $p$ assets be the reference assets; the $q=n-p$ remaining assets are the test assets. The system that defines the SDF -- $m_{c_{j}, t}$ for the $n$ assets is,

$$
\begin{aligned}
& R_{t}-E\left(R_{t} \mid m_{c_{1}}\right)=v_{1, t} ; E\left(\varepsilon_{t}\right)=0, \text { where } \varepsilon_{t}^{\prime}=\left(v^{\prime}{ }_{l, t} v_{2, t}^{\prime}\right), \\
& R_{t}-E\left(R_{t} \mid m_{c_{2}}\right)=v_{2, t} \\
& m_{c_{j}, t}=\sum_{p=1}^{5(7)} \beta_{p, j} r_{p, t}+\sum_{q=6(8)}^{7(9)} \beta_{q, j} r_{q, t}+c_{j} ; \quad E\left(m_{c_{j}, t}\right)=c_{j}, j=1,2,
\end{aligned}
$$

where $r_{t}=R_{t}-E\left(R_{t}\right)$, and $m_{c_{j}, t}$ is the SDF as a function of a pre-specified risk-free rate, $c_{j}$.

The null hypothesis of unconditional spanning ( $p$ reference assets are sufficient to span all $p+q=n$ assets) is imposed through the parameter restrictions, $\beta_{q, 1}=\beta_{q, 2}=0$, because the $q$ test assets are excluded from the SDF. Unconditional spanning implies that the average pricing error is zero for all asset returns, within the limits of statistical tolerance. The Hansen J-Statistic (Hansen, 1982; Hansen \& Singleton, 1982) is used to evaluate the overidentifying conditions implied by spanning. It is distributed $\chi^{2}$ with degrees of freedom equal to the number of overidentifying conditions. ${ }^{28}$

\section{1.b. Results:}

Table 3 displays the results of this test for three pairs of test assets for $B E / M E$, $M V E$, and the 2-way sorted portfolios, by country. We report results for the extreme pairs of test assets (1\&7 for the $B E / M E$ and $M V E$ sorting, and $3 \& 7$ for the 2-way sorting), for the middle pairs of test assets ( $3 \& 5$ for the $B E / M E$ and $M V E$ sorting, and $2 \& 6$ for the 2way sorting), and for one set of in-between pairs (2\&6 for the BE/ME and $M V E$ sorting,

28 There are $2 n$ orthogonality conditions, $2 p$ parameters to estimate, and $2 q$ overidentifying conditions. 
and $1 \& 9$ for the 2-way sorting). ${ }^{29}$ The extreme pair of portfolios have the largest and smallest values of the instrument they are sorted on $(B E / M E$, or $M V E)$. The middle pair of portfolios have the middle and adjacent values of the instrument they are sorted on, while the in-between portfolios are neither the extreme nor the most similar; of course there are many possible "in-between" portfolio pairs. Entries are shaded if they statistically reject spanning at the $5 \%$ level; we report p-values for the tests.

Overall, the spanning hypothesis is rejected in 27 out of 63 cases. However, there are significant differences in rejection rates across the test assets. When the extreme pairs are the test assets $(1 \& 7 / 3 \& 7)$, and thus excluded from the SDF, spanning fails in 14 out of 21 cases $(67 \%)$. But when the middle pairs are excluded spanning fails in only 5 out of 21 cases $(24 \%){ }^{30}$

This result shows that SDFs that include the extreme portfolios span much more successfully than those that exclude them! This is clear evidence that the " $B E / M E$ " and the " $M V E$ " effect exist even under this very general asset pricing model. It also supports the practice of using an $H M L$ portfolio as a pricing "factor" in the context of the CAPM. At the same time, our results also show that the spanning of even when the extreme portfolios are included is far from satisfactory. In 4 of the 7 countries spanning fails in this case (CAN, DEU, GBR, JPN) in at least one of the rankings.

An unconditional SDF -- $m_{t^{--}}$can account for differences in average returns because each portfolio generally has a different covariance with the SDF. As shown in Appendix B, $E\left(R_{i}\right)=\frac{1-\operatorname{cov}\left(R_{i}, m_{t}\right)}{E\left(m_{t}\right)}$, where $\operatorname{cov}\left(R_{i}, m_{t}\right)=\sum_{p} \beta_{p} \operatorname{cov}\left(R_{i, t}, r_{p, t}\right) .{ }^{31}$ Our

29 Our numbering convention for the portfolios is shown below.

$B E / M E$ or $M V E$ Stocks

\begin{tabular}{||lllllcc|}
\hline Smallest & & & & \multicolumn{3}{c|}{ Largest } \\
\hline 1 & 2 & 3 & 4 & 5 & 6 & 7 \\
\hline
\end{tabular}

\begin{tabular}{|c|c|c|c|}
\hline \multicolumn{4}{|c|}{ Two-Way Sort } \\
\hline & \multicolumn{3}{|c|}{$B E / M E$} \\
\hline & Smallest & & Largest \\
\hline Smallest & 1 & 2 & 3 \\
\hline$M V E$ & 4 & 5 & 6 \\
\hline Largest & 7 & 8 & 9 \\
\hline
\end{tabular}

30 The probability of obtaining this result by chance is $0.00 \%$ at the $5 \%$ level. The probability of obtaining 5 or more rejections in 21 tries by chance is $0.33 \%$ if the tests are uncorrelated.

31 We drop the subscript $c_{j}$, that refers to the risk free rate for convenience. 
results show that when the extreme portfolios are part of $m_{t}$, the resulting covariances do a better job of replicating average returns than when the extreme portfolios are excluded.

The standard approach for improving the ability of the SDF to span the assets is to augment it with objects of the form $\theta_{p} Z_{t-1} r_{p}$, where $Z_{t-1}$ is a lagged conditioning variable or "instrument" (for example $B E / M E$ ), and $\theta_{p}$ is an additional coefficient. These objects are referred to as "managed portfolios" in some applications. The risk premium of each asset now becomes time varying, $\operatorname{cov}\left(R_{i}, m_{t}\right)=\sum_{p}\left(\beta_{p}+\theta_{p} Z_{t-1}\right) \operatorname{cov}\left(R_{i, t}, r_{p, t}\right)$. In our application, the conditioning variables $Z_{t}(B E / M E$ or $M V E)$ is specific to the portfolios, as we discuss below. Therefore, this formulation of the SDF allows both for the conditional risk premium to depend on the instantaneous value of the instrument and for the average risk premium to depend its average level.

In the next two subsections we investigate if augmenting the SDF by adding $B E / M E, M V E$, and other macro and financial variables in conjunction with $B E / M E$ improves its pricing and spanning performance.

\subsection{Conditional Spanning with $B E / M E$ and $M V E$ :}

In this section we perform two sets of tests:

1. The first test examines the statistical contribution of $B E / M E$ and $M V E$ to the "fit" of the SDFs when they are conditioned by $B E / M E$ and $M V E$ as instruments. This is essentially a time series test; all the assets are included in the SDF.

2. The second test investigates how well these conditional SDFs span or price. This is our conditional spanning test.

\section{2.a Test Specifications:}

Let $\boldsymbol{Z}_{s}$ refer to the type of conditioning variable ( $s=B E / M E$ or $M V E$ ); the second subscript in $\boldsymbol{Z}_{s, i}$ indicates that the $i^{\text {th }} \boldsymbol{Z}_{s}$ is specific to the $i^{\text {th }}$ portfolio. The conditioning information introduces new variables of the form $Z_{t-1} R_{i t}$ to the SDF. We require the pricing errors of each portfolio to be orthogonal only to the own lagged $B E / M E$ or $M V E$. Thus these new variables are the products of the portfolio specific $Z_{s, i, t-1}$ (alternately $B E / M E$ 
and $M V E$ ) with the corresponding portfolio returns. ${ }^{32}$ The set of the new variables can be represented by the Hadamard product, $R_{t} \oplus Z_{s, t-l}$, rather than the Kroenecker product, $R_{t} \otimes Z_{s, t i} ;$ the latter would imply that the pricing errors for each portfolio are required to be orthogonal to the $B E / M E$ or $M V E$ of all the portfolios.

Let $R_{t}$ and $Z_{s, t-1}$ be $n$-dimensional vectors, respectively, of date $t$ returns on $n$ assets and $n$ portfolio-specific conditioning variables. The system that defines the volatility bound for the $n$ assets is,

$$
\begin{aligned}
& R_{t}-E\left(R_{t} \mid m_{c_{1}}\right)=v_{1, t}, \\
& R_{t}-E\left(R_{t} \mid m_{c_{2}}\right)=v_{2, t},
\end{aligned} ; \quad E\left(\varepsilon_{t}\right)=0, E\left(\varepsilon_{t} \oplus Z_{s}\right)=0, \text { where } \varepsilon_{t}=\left(v_{l, t}^{\prime} v_{2, t}^{\prime}\right)^{\prime} .
$$

The SDF is,

$$
m_{c_{j}, t}=\sum_{i=1}^{7(9)}\left(\beta_{i, j}+\theta_{i, j} Z_{s, i, t-1}\right) r_{i, t}+c_{j} ; j=1,2 ; E\left(m_{c_{j}, t}\right)=c_{j}, j=1,2,
$$

where $s=B E / M E, M V E, r_{t}=R_{t}-E\left(R_{t}\right), m_{c_{j}, t}$ is the SDF, and $c_{j}$ is the pre-specified risk free rate. Note that adding conditioning variables to the SDF is equivalent to modeling time variation in the coefficients of the SDF with the conditioning variables.

We test the importance of $B E / M E$ or $M V E$ for pricing by testing the null hypothesis that the coefficients $\theta_{i}$ of the SDFs are not statistically significant $\left(\theta_{i}=0\right)$. The test statistic is the Wald test applied to the augmented SDF; the statistic is $\chi^{2}$-distributed where the degrees of freedom are the number of overidentifying restrictions. ${ }^{33}$

The conditional spanning test is performed on the above system and is exactly analogous to the unconditional spanning test (equations 2a-b), except that the SDF has nonlinear coefficients; equation (2b) is amended as follows:

\footnotetext{
32 In the standard specification every asset return is required to be orthogonal to all the conditioning variables. In our application this approach would result in 7 or 9 orthogonality conditions for each portfolio, which would produce highly unreliable results. The specification we use requires only one orthogonality condition for each portfolio.

33 Conditioning on $w \boldsymbol{Z}_{t-1}$ variables adds $2 n w$ orthogonality conditions for a total of $2 n(w+1)$ conditions. $2 n$ parameters are estimated, which leaves $2 n w$ overidentifying conditions. Since $w=1$, for SDFs conditioned on either $B E / M E$ or $M V E$ there are $2 n$ overidentifying conditions.
} 


$$
m_{c_{j}, t}=\sum_{p=1}^{5(7)}\left(\beta_{p, j}+\theta_{p, j} Z_{s, p, t-1}\right) r_{p, t}+\sum_{q=6(8)}^{7(9)}\left(\beta_{q, j}+\theta_{q, j} Z_{s, q, t-1}\right) r_{q, t}+c_{j} ; E\left(m_{c_{j}, t}\right)=c_{j}
$$

The conditional spanning hypothesis ( $p$ reference assets are sufficient to span all $p+q=n$ assets) is tested by imposing the parameter restrictions, $\beta_{q, 1}=\beta_{q, 2}=\theta_{q, 1}=$ $\theta_{q, 2}=0$, because the $q$ test assets are excluded from the SDF. The null hypothesis of conditional spanning implies that the average pricing error with the restricted SDF is zero for all the assets. The test statistic is the Hansen J-statistic, which is $\chi^{2}$-distributed. ${ }^{34}$

\section{2.b. Results:}

In Table 4, panel A we report p-values from Wald tests of the null hypothesis, that the SDF coefficients for $B E / M E$ and $M V E\left(\theta_{i, j}=0 \forall i, j\right)$ are insignificant. Entries significant at the $5 \%$ level are shaded. $B E / M E$ is not significant in only 1 case out of 21 (Germany --DEU-- $M V E$-sort) and $M V E$ is not significant in 3 cases out of 21. Clearly, both of these variables significantly improve the overall "fit" of the SDFs, separately. This finding implies that the pricing errors of the unconditional SDF are not orthogonal to $B E / M E$ and $M V E$. Alternatively, the hypothesis that the SDF coefficients are not time-varying is rejected. We conclude that modeling nonlinearities in the SDF coefficients with our two instruments significantly improves the SDF's time series fit. This finding is in accord with the literature that documents the importance of $B E / M E$ and $M V E$ in time series regressions.

However, the improved time series fit does not guarantee that the SDFs augmented by $B E / M E$ or $M V E$ will span better. Table 4, panel B reports the spanning performance of these nonlinear (or conditional) SDFs. It is evident that their spanning performance is not materially different from the linear (or unconditional) ones. Overall, when $B E / M E$ is the instrument, spanning is rejected for 32 out of 63 cases, and once again there are major differences across test assets. When the extreme pairs are excluded from the SDF, spanning fails in 17 out of 21 cases (81\%), at the 5\% level. But when the middle 
pairs are excluded, spanning fails in only 6 out 21 cases (28\%). The results when $M V E$ is the instrument are very similar. The nonlinearity of the SDFs does not improve their spanning ability, even though it improves the time series fit. Just as in the unconditional case, when the extreme $B E / M E$ and $M V E$ portfolios are excluded from the SDF spanning is overwhelmingly rejected.

Our results to this point establish the following:

(i) The $B E / M E$ and $M V E$ effects exist in all the countries we study, even when we use a very general pricing model. The evidence for this is that spanning overwhelmingly fails, when the extreme $B E / M E$ and $M V E$ portfolios are excluded from the SDFs and that SDFs conditioned by $B E / M E$ and $M V E$ "fit" the data significantly better.

(ii) The conditional SDFs do not span better than the unconditional ones.

These findings leave open the possibility that our instruments (BE/ME and $M V E)$ proxy for other economic variables or that additional variables might help span the assets.

\subsection{Alternative Macro and Financial Variables for Conditional Spanning}

In this section we broaden our investigation of the importance of $B E / M E$ by testing 15 alternative variables in the SDF, along with $B E / M E$, to determine,

(i) if $B E / M E$ simply proxies for some other variable, and,

(ii) if adding any of these variables can improve spanning performance.

We choose to focus only on $B E / M E$ both because $B E / M E$ performs somewhat better than $M V E$, and because the range of $M V E$ for some of the countries is quite narrow.

We test the following 15 macro and financial variables as additional instruments in the $\mathrm{SDF}^{35}$

\footnotetext{
34 Since spanning implies that average pricing errors are zero, only the average pricing error of the test assets are tested against zero. Therefore, the degrees of freedom are the same as in the unconditional spanning case; they are equal to $2 q$, which is always four.

35 This list contains most of the important variables that have been used by various studies to build empirical asset pricing models. In almost all cases there are counterparts to the U.S. and or the global variables. For example, the counterpart of $T B 3 M$ would be $L S T B$, etc. However, there are no available counterparts to the $A A A$ and $B A A$ rate in foreign countries. Therefore, only the US junk bond premium is used.
} 
$r_{g}(t-1) \quad$ MSCI Global market return (in local currency units),

Gpgold(t-1) Gold price growth rate, in local currency units,

$i_{\text {euro }}(t-1) \quad$ The Eurodollar rate converted to the local currency,

$\operatorname{TB} 1 M(t-1) \quad$ The 1-month U.S. T-Bill rate, in local currency,

$T P R E(t-1) \quad$ The U.S. "term" premium, $T B 30 Y-T B 3 M$, in local currency,

$J P R E(t-1) \quad$ The U.S. "junk bond" premium, $B A A-A A A$ rates, in local currency,

$W D I V P R E(t-1) \quad$ The global dividend-to-price ratio,

$W G I N D P(t-1) \quad$ Growth rate of the global industrial production index,

WINFL(t-1) The global inflation index,

$\operatorname{LSTB}(t-1) \quad$ The local short term interest rate,

$\operatorname{LTPRE}(t-1) \quad$ The local "term" premium, long-term rate $-\operatorname{LSTB}$,

$\operatorname{LDIVPRE}(t-1) \quad$ The local dividend-to-price ratio,

$\operatorname{LGINDP}(t-1) \quad$ Growth rate of the local industrial production,

GLM2(t-1) Growth rate of the local money supply, $M 2$,

$\operatorname{LINFL}(t-1) \quad$ The local inflation index, CPI.

\section{3.a Test Specification:}

As before, $\boldsymbol{R}_{t}$ and $\boldsymbol{Z}_{t-1}$ are $n$-dimensional vectors, respectively, of date $t$ returns on $n$ assets and $n$ portfolio specific $B E / M E$ s. Let $V_{k, t-1}$ be the $k^{\text {th }}$ instrument (of 15 listed above) to be considered. We require the pricing errors of each portfolio to be orthogonal to its own $B E / M E$ and to $V_{k}$. The system that defines the volatility bound for the $n$ assets is,

$$
\begin{aligned}
& R_{t}-E\left(R_{t} \mid m_{c_{1}}\right)=v_{1, t} \\
& R_{t}-E\left(R_{t} \mid m_{c_{2}}\right)=v_{2, t}
\end{aligned} ; \quad E\left(\eta_{t}\right)=0, E\left(\varepsilon_{t} \oplus Z_{t-1}\right)=0, E\left(\varepsilon_{t} \otimes V_{k}\right)=0, \eta_{t}=\left(v_{l, t}^{\prime} v_{2, t}^{\prime}\right)^{\prime} .
$$

The corresponding SDF is,

$$
m_{c_{j}, t}=\sum_{i=1}^{7(9)}\left(\beta_{i, j}+\theta_{i, j} Z_{i, t-1}+\lambda_{i, j} V_{k, t-1}\right) r_{i, t}+c_{j} ; j=1,2 ; E\left(m_{c_{j}, t}\right)=c_{j}
$$

where, $r_{t}=R_{t}-E\left(R_{t}\right), j=1,2$.

We perform three tests:

(i) A test of the null hypothesis that none of these new variables is significant in pricing, i.e, $\lambda_{i, j}=0, \forall i, j$, and,

(ii) A test of the null hypothesis that $B E / M E$ proxies for one of the new variables, i.e., $\theta_{i, j}=0, \forall i, j$. This is a test of the robustness of $B E / M E$. 
A conditional spanning test of the reference-asset SDFs conditioned by $B E / M E$ and the new variables, one of at a time.

If for the $k^{\text {th }} V_{k}$ the null hypothesis $\left(\lambda_{i, j}=0 \forall i, j\right)$ is rejected in the presence of the $B E / M E$ s we may conclude that the $k^{\text {th }} V_{k}$ enhances the time-series "fit" of the SDF. If the null hypothesis $\left(\theta_{i, j}=0 \forall i, j\right)$ is rejected in the presence of the $k^{\text {th }} V_{k}$, we may conclude that the $k^{\text {th }} V_{k}$ does not replace or supercede $B E / M E$ as an instrument, and that $B E / M E$ is robust with respect to the $k^{\text {th }} V_{k}$ in the SDF. The test statistic is the Wald test of the constrained SDF, where each set of coefficients $\left(\lambda_{i, j}\right.$ and $\left.\theta_{i, j}\right)$ are tested jointly against the null hypothesis that they are zero. The statistic is $\chi^{2}$-distributed where the degrees of freedom are the number of overidentifying restrictions. ${ }^{36}$

The third test is a spanning test of the same form as in section 3.3.2 above, except that the time-variation of the SDF coefficients is modeled with two variables.

$$
\begin{aligned}
m_{c_{j}, t}= & \sum_{p=1}^{5(7)}\left(\beta_{p, j}+\theta_{p, j} Z_{p, t-1}+\lambda_{p, j} V_{k, t-1}\right) r_{p, t}+\sum_{q=6(8)}^{7(9)}\left(\beta_{q, j}+\theta_{q, j} Z_{q, t-1}+\lambda_{q, j} V_{k, t-1}\right) r_{q, t}+c_{j} ; \\
& E\left(m_{c_{j}, t}\right)=c_{j}, j=1,2 .
\end{aligned}
$$

The conditional spanning hypothesis ( $p$ reference assets are sufficient to span all $p+q=n$ assets) implies the parameter restrictions, $\beta_{q, 1}=\beta_{q, 2}=\theta_{q, 1}=\theta_{q, 2}=0$, because the $q$ test assets are excluded from the SDF. Conditional spanning implies that average returns for all the assets are correctly priced with this restricted SDF. As before, the test statistic is the $\mathrm{J}$-Statistic, which is $\chi^{2}$-distributed. ${ }^{37}$

\section{3.b. Results:}

First we explore whether any of the 15 instruments add significantly to the pricing accuracy of the SDFs when tested one at a time in the presence of $B E / M E$. For each country, at least 10 of the instruments are significant for each portfolio ranking. On

\footnotetext{
36 The $\boldsymbol{Z}_{i, t-1}$ and $V_{k, t-1}$ variables each adds $2 n$ orthogonality conditions. Thus there are a total of $4 n$ overidentifying conditions.

37 See footnote No. 36.
} 
average, 12 of the variables are significant for some portfolio rankings, and in some cases all 15 are significant. If we consider one portfolio ranking and one instrument as one try, there are 45 tries for each country. The minimum proportion of "significant tries" (the instrument is significant at the 5\% level) is $73 \%$ for Canada, France and Great Britain, and the maximum is $91 \%$ for the US. We do not tabulate the results here because of space considerations; detailed results are available from the authors.

None of the instruments is significant for all the countries and all the portfolio rankings, at the 5\% level. The local short term interest rate, the growth rate of local Industrial Production, and local Inflation (LSTB, GLINDP, LINFL), are significant in at least $90 \%$ of the 21 "tries" (7 countries, 3 portfolio rankings each). The least successful instrument is the global Industrial Production index, WGINDP, significant in only $57 \%$ of the "tries".

These results show clearly that these instruments, as a group, significantly improve the time series "fit" of the SDFs, for all the countries. Thus, they are legitimate candidates to consider as alternatives to $B E / M E$.

Next we investigate the robustness of $B E / M E$ in the presence of these alternative instruments, i.e., whether some of these instruments displace it in the SDF. When the 15 instruments are added to the SDFs one at a time, $B E / M E$ is not significant only $11 \%$ of time, at the 5\% significance level. Almost half of the insignificant $B E / M E$ coefficients come from the DEU (Germany) $M V E$-sorted portfolios. ${ }^{38}$ But this is the only instance in which $B E / M E$ is not significant, even by itself. The tests show clearly that $B E / M E$ is not replaced in the SDFs by these alternative instruments. Their contributions to pricing are independent and complementary to that of $B E / M E$.

Finally, we investigate the conditional spanning hypothesis; whether augmenting the SDFs by $B E / M E$ and by these 15 instruments one at a time, improves spanning performance. It is not possible in this space to present all 945 test results; thus table 5, Panel A summarizes the results, and Panel B displays results for the "best" scenarios.

38 In this sort, $B E / M E$ has a particularly narrow range; see Table 1, Panel B. 
Table 5, Panel A shows that the spanning performance of the SDFs is very much in line with those in the earlier sections: The SDFs again rarely span when the extreme portfolios are the test assets. Spanning is much more common when the extreme pair of portfolios are included in the reference assets, and once again they are most frequent when the middle pair of portfolios are the test assets. ${ }^{39}$

There are 135 SDFs formed for each country; that is 3 portfolio rankings, 3 configurations of test assets and 15 instruments applied to each. Except for Canada, there is at least one SDF (a configuration of reference assets and an additional instrument) that spans all 3 rankings.

The rightmost column of Panel A lists the instruments that are most successful in spanning, for each country. For France and the U.S. almost all the instruments work equally well but for other countries there are two or three instruments that do better than the rest. The world Dividend-Price ratio, WDIVPRE, and local Industrial Production, GLINDP, seem to do quite well across countries.

To get a better understanding of the spanning behavior of the SDFs in the presence of these instruments, we report two best-scenario cases in Panel B of Table 5. The lefthand columns report the spanning performance of WDIVPRE, which is the bestperforming instrument across all the countries. The right-hand columns report the spanning performance of the "best" instrument for each country; best means that it spans most frequently across the various "tries" in that country. ${ }^{40}$ To provide a clear picture of the additional contribution of these instruments we use the following notation in the table. We place "***" where spanning failed both with $B E / M E$ and with $B E / M E$ plus the instrument; we place "a.s." where spanning was achieved already with $B E / M E$ (from Table 4, Panel B). Finally, the numbers in the table are p-values for the spanning hypothesis, and they appear only where spanning failed with $B E / M E$ alone but was achieved when the instrument was added to the SDF.

\footnotetext{
39 The $M V E$-sort in Germany is the exception. In that case, all the instruments help span the extreme portfolios and perversely, SDFs that include the extreme portfolios fail to span.

40 We do not use WDIVPRE the "best" instrument whenever there is another with equal performance, in order to reduce duplication with the right-hand columns.
} 
The most striking result is that these instruments make only a minor contribution to spanning. The best instruments do not help span the extreme portfolios that are rarely spanned with $B E / M E$ alone. In 14 of 63 instances spanning fails for the middle and the inbetween portfolios with $B E / M E$ alone as an instrument; spanning is achieved in only 4 of these cases with WDIVPRE.

Neither these nor any of the other instruments consistently help span (i.e., their associated SDFs do not span all three rankings of the underlying assets). For Australia, France, Japan, and the U.S., the SDFs span the middle pair (and in some cases the inbetween pair) when WDIVPRE is in the SDF, for all three rankings. When the "best" instrument for each country is used, spanning performance is slightly better, particularly for the in-between pairs of portfolios.

We conclude that:

(i) The book-to-market effect continues to persist for all the countries in the presence of several plausible economic variables.

(ii) One or more macroeconomic variables, together with $B E / M E$, frequently span test assets, as long as the SDFs contain the extreme portfolios as reference assets.

(iii) Average returns are not completely explained by a model that includes the extreme portfolios (i.e., a BE/ME arbitrage portfolio). Spanning still fails in several instances even when extreme portfolios are included in the discount factor.

\section{CONCLUSION}

The tests we report provide very strong evidence that in all seven countries we examine over the 1982-94, average returns are high when Book Equity to Market Equity ratio $(B E / M E)$ is high; also they are high when Market Value (MVE) is low. The evidence in favor of $M V E$ is somewhat weaker.

Regression analysis based on Jensen's alpha, and the Fama \& French $H M L$ portfolio tests are consistent with those reported in the literature. However, these tests have serious weaknesses, both because they are based on a specific asset-pricing model and because there are potentially serious simultaneity biases in the estimates of these models, when OLS methods are employed. 
We discuss and implement a set of spanning tests based on the HansenJagannathan Stochastic Discount Factor (SDF) approach, which only requires that the Law of One Price is satisfied. These tests suffer neither from the need to specify an asset pricing model nor from potential simultaneity biases. Some of the tests are for unconditional pricing while others use a variety of common macroeconomic and financial variables.

Consistent with recent literature, we conclude that the $B E / M E$ and $M V E$ "effects" are international in character. They remain strong under this general model and against a variety of alternatives macroeconomic and financial "conditioning" variables. These variables do not substitute for $B E / M E$ but instead they improve the time-series fit of the pricing model significantly.

However, contrary to the findings in the literature, we cannot account completely for the cross-sectional average return differences of the $B E / M E$ - and $M V E$-sorted portfolios with any of the SDFs we construct, i.e., the assets are not universally spanned by our SDFs. The SDFs that include portfolios with extreme values of $B E / M E$ or $M V E$ span much more frequently than those SDFs that exclude those portfolios. This is similar to the practice of including the $H M L$ portfolio in CAPM-based models. For some of the countries we find at least one instrument, that together with $B E / M E$ results in SDFs that span the assets.

The evidence presented here suggest that the $B E / M E$ and $M V E$ effects are not artifacts of the inadequacies of the augmented CAPM as an asset pricing model or of omitting potentially important macro and financial variables from the models. Finally, our finding, that SDFs that omit the extreme-valued portfolios do not span, suggests that the underlying "factors" that summarize the return-generating process are not present in all the sorted portfolios we have constructed, even though these portfolios are well diversified in other dimensions. 


\section{BIBLIOGRAPHY}

[1] Andrews, Donald W.K., 1991, Heteroskedasticity and autocorrelation consistent covariance matrix estimation, Econometrica 59, 817-858.

[2] Arellano, Manuel, and Steve Bond, 1991, Some tests of specification for panel data: Monte Carlo evidence and an application to employment equations, Review of Economic Studies 58, 277-297.

[3] Banz, Rolf W., 1981, The relationship between return and market value of common stocks, Journal of Financial Economics 9, 3-18.

[4] Basu, Sanjoy, 1977, Investment performance of common stocks in relation to their price earnings ratios: A test of the efficient market hypothesis, Journal of Finance 32:3, 663-682.

[5] Basu, Sanjoy, 1983, The relationship between earnings yield, market value and return for NYSE common stocks: Further evidence, Journal of Financial Economics 12, 129-156.

[6] Black, Fischer, 1993, Beta and return, Journal of Portfolio Management, 8-17.

[7] Breeden, Douglas T., 1979, An intertemporal asset pricing model with stochastic consumption and investment opportunities, Journal of Financial Economics 7, 265-296.

[8] Breen, William J., and Robert A. Korajczyk, 1995, On the selection biases in book-to-market based tests of asset pricing models, Working Paper \#167, Northwestern University.

[9] Brown, Phillip, Alan Kleidon, and Terry Marsh, 1983, New evidence on size related anomilies in stock prices, Journal of Finanical Economics 12, 33-56.

[10] Campbell, John Y., 1987, Stock returns and the term structure, Journal of Financial Economics 18, 373-399.

[11] Capaul, Carlo, Ian Rowley, and William Sharpe, January-February 1993, International value and growth stock returns, Financial Analyst Journal 41:1, 27-36.

[12] Chan, Louis C., Yasushi Hamao, and Josef Lakonishok, 1991, Fundamentals and stock returns in Japan, Journal of Finance 46, 1739-1764.

[13] Chan, K.C., and Nai-fu Chen, 1991, Structural and return characteristics of small and large firms, Journal of Finance 46, 1467-1484.

[14] Daniel, Kent and Sheridan Tittman, 1997, Evidence on the characteristics of cross-sectional variation in stock returns, Journal of Finance 52, 1-34.

[15] De Santis, Giorgio, 1993, Volatility bounds for stochastic discount factors: Tests and implications from international stock returns, unpublished Ph.D. dissertation, The University of Chicago. 
[16] De Santis, Giorgio, 1994, Asset Pricing and Portfolio Diversification: Evidence from Emerging Financial Markets, in Investing in Emerging Markets ed. Mike Howell, Euromoney Books.

[17] Fama, Eugene F., and Kenneth French, 1992, The cross-section of expected stock returns, Journal of Finance 47, 427-465.

[18] Fama, Eugene F., and Kenneth French, 1993, Common risk factors in the returns on stocks and bonds, Journal of Financial Economics 33, 3-56.

[19] Fama, Eugene F., and Kenneth French, 1995, Size and book-to-market factors in earnings and returns, Journal of Finance 50, 131-155.

[20] Fama, Eugene F., and Kenneth French, 1997, Value versus growth: the international evidence, forthcoming, Journal of Finance.

[21] Ferguson, Michael, and Richard Shockley, 1999, Equilibrium 'Anomalies', Kelley School of Business, Indiana University, working paper.

[22] Ferson, Wayne, Sergei Sarkissian and Timothy Simin, 1999, The Alpha Factor Asset Pricing Model: A Parable, Journal of Financial Markets 2, 49-68.

[23] Ferson, Wayne E., and Campbell R. Harvey, 1993, The risk and predictability of international equity returns, Review of Financial Studies 6, 527-566.

[24] Ferson, Wayne E., and Stephen R. Foerster, 1994, Finite sample properties of the Generalized Method of Moments in tests of conditional asset pricing models, Journal of Financial Economics 36, 29-55.

[25] Ferson, Wayne E., Stephen R. Foerster, and Donald B. Keim, 1993, General tests of latent variable models and mean-variance spanning, Journal of Finance 48, 131-156.

[26] Gibbons, Michael R., and Wayne Ferson, 1985, Testing asset pricing models with changing expectations and an unobservable market portfolio, Journal of Financial Economics 14, 217-236.

[27] Hansen, Lars P., 1982, Large sample properties of generalized method of moments estimators, Econometrica 50, 1029-1054.

[28] Hansen, Lars P., and Kenneth J. Singleton, 1982, Generalized instrumental variables estimation of nonlinear rational expectation models, Econometrica 50, 1269-1286.

[29] Hansen, Lars P., and Ravi Jagannathan, 1991, Implications of security market data for models of dynamic economies, Journal of Political Economy 99, 225-262.

[30] Hansen, Lars P., and Scott F. Richard, 1987, The role of conditioning information in deducing testable restrictions implied by dynamic asset pricing models, Econometrica 55, 587-613.

[31] Harvey, Campbell R., 1989, Time-varying conditional covariances in tests of asset pricing models, Journal of Financial Economics 24, 289-317. 
[32] Harvey, Campbell R., 1991, The world price of covariance risk, Journal of Finance 46, 111-158.

[33] Haugen, Robert, 1994, The New Finance: The Case Against Efficient Markets (Prentice Hall, Englewood Cliffs, New Jersey).

[34] Heston, Steven, Geert Rouwenhorst, and Roberto Wessels, 1997, The role of beta and size in the cross-section of european stock returns, forthcoming, European Financial Management.

[35] Huberman, Gur, and Shmuel Kandel, 1987, Mean-variance spanning, Journal of Finance 42, 873-888.

[36] Huberman, Gur, Shmuel Kandel, and Robert F. Stambaugh, 1987, Mimicking portfolios and exact arbitrage pricing, Journal of Finance 42, 1-9.

[37] Ikenberry, David, Joseph Lakonishok, and Theo Vermaelen, 1994, Market underreaction to open market repurchases, Rice University Jesse H. Jones Graduate School of Administration Working Paper No. 106.

[38] Ingersoll, Jonathan E. Jr., 1987, Theory of Financial Decision Making (Rowman \& Littlefield, New Jersey).

[39] Jagannathan, Ravi, and Zhenyu Wang, 1993, The CAPM is alive and well, Staff Report 165, Federal Reserve Bank of Minneapolis.

[40] Keim, Donald B., 1983, Size-related anomalies and stock return seasonality, Journal of Financial Economics 12, 13-32.

[41] Knez, Peter, 1994, Pricing money market securities with stochastic discount factors, manuscript, The University of Wisconsin-Madison.

[42] Kothari, S.P., Jay Shanken, and Richard G. Sloan, 1995, Another look at the cross-section of expected stock returns, Journal of Finance 50, 1541-1578.

[43] Lo, Andrew W., and A. Craig MacKinlay, 1990a, Data snooping and biases in tests of financial models, Review of Financial Studies 3, 431-468.

[44] Loughran, T., and Jay Ritter, 1994, The new issues puzzle, unpublished University of Iowa working paper.

[45] MacKinlay, A. Craig, 1995, Multifactor models do not explain deviations from the CAPM, Journal of Financial Economics 38, 3-28.

[46] MacKinlay, A. Craig, and Matthew Richardson, 1991, Using the generalized method of moments to test mean-variance efficiency, Journal of Finance 46, 511-528.

[47] Merton, Robert C., 1973, An intertemporal capital asset pricing model, Econometrica 41, 867-887.

[48] Newey, Whitney K., and Kenneth D. West, 1987, A simple, positive semi-definite, heteroskedasticity and autocorrelation consistent covariance matrix, Econometrica 55, 703-708. 
[49] Reiganum, M.R., 1981, Misspecification of capital asset pricing: Empirical anomalies based on earnings yields and market values, Journal of Financial Economics 9, 19-46

[50] Ross, Stephen A., 1976, The arbitrage theory of capital asset pricing, Journal of Economic Theory 13, 341-360.

[51] Rouwenhorst, K. Geert, 1998, Local return factors and turnover in emerging stock markets, School of Management, Yale University, unpublished working paper.

[52] Shanken, Jay, 1990, Intertemporal asset pricing, Journal of Econometrics 45, 99-120.

[53] Sharpe, W., 1964, Capital asset prices: A theory of market equilibrium under conditions of risk, Journal of Finance 19, 425-442.

[54] Spiess, Katherine D., and John Affleck-Graves, 1994, The long-run performance of seasoned equity offerings, unpublished University of Norte Dame Department of Finance and Economics working paper.

[55] Stattman, Dennis, 1980, Book values and expected stock returns, The Chicago MBA: A Journal of Selected Papers 4, 25-45.

[56] Stutzer, Michael, 1993, A Bayesian approach to diagnosis of asset pricing models, manuscript, Department of Finance, Carlson School of Management, University of Minnesota. 
TABLE 1: Descriptive Statistics for the Portfolios

PANEL $A^{1}$

Sorted by Book-to-Market Ratio

\begin{tabular}{|l|ccccccc||}
\hline & \multicolumn{7}{|c||}{ Book-to Market Ratios (upper) } \\
& \multicolumn{7}{|c||}{ and } \\
& Number of Firms (lower) \\
\hline Country & Low-1 & $\mathbf{2}$ & $\mathbf{3}$ & $\mathbf{4}$ & $\mathbf{5}$ & $\mathbf{6}$ & High-7 \\
\hline AUS & 0.317 & 0.508 & 0.626 & 0.751 & 0.915 & 1.166 & 2.077 \\
& 20 & 20 & 19 & 19 & 19 & 19 & 19 \\
\hline CAN & 0.259 & 0.486 & 0.643 & 0.801 & 0.983 & 1.209 & 2.739 \\
& 44 & 44 & 44 & 44 & 43 & 43 & 43 \\
\hline FRA & 0.218 & 0.349 & 0.453 & 0.567 & 0.658 & 0.799 & 1.482 \\
& 13 & 13 & 13 & 12 & 12 & 12 & 12 \\
\hline DEU & 0.190 & 0.336 & 0.428 & 0.521 & 0.650 & 0.857 & 1.923 \\
& 20 & 20 & 20 & 20 & 20 & 20 & 19 \\
\hline GBR & 0.187 & 0.343 & 0.459 & 0.585 & 0.782 & 1.083 & 1.908 \\
& 92 & 92 & 91 & 91 & 91 & 91 & 91 \\
\hline JPN & 0.141 & 0.238 & 0.305 & 0.368 & 0.436 & 0.522 & 0.717 \\
& 151 & 151 & 151 & 151 & 151 & 151 & 150 \\
\hline USA & 0.199 & 0.385 & 0.527 & 0.674 & 0.841 & 1.068 & 1.558 \\
& 314 & 313 & 313 & 313 & 313 & 313 & 313 \\
\hline \hline
\end{tabular}

\begin{tabular}{||l|ccccccc||}
\hline & \multicolumn{7}{|c||}{ Market Value $^{2}$ (upper) and } \\
& \multicolumn{7}{|c|}{ Earnings to Price Ratio (lower) } \\
\hline Country & Low-1 & $\mathbf{2}$ & $\mathbf{3}$ & $\mathbf{4}$ & $\mathbf{5}$ & $\mathbf{6}$ & High-7 \\
\hline AUS & 1,077 & 957 & 768 & 711 & 629 & 386 & 257 \\
& 0.028 & 0.053 & 0.041 & 0.059 & -0.046 & -0.112 & -0.213 \\
\hline CAN & 343 & 392 & 450 & 520 & 492 & 321 & 230 \\
& -0.057 & 0.005 & 0.023 & 0.017 & 0.039 & 0.011 & 1.586 \\
\hline FRA & 225 & 443 & 228 & 579 & 826 & 773 & 683 \\
& -0.002 & 0.024 & 0.016 & 0.035 & 0.039 & 0.045 & 0.030 \\
\hline DEU & 5,126 & 4,822 & 3,587 & 2,585 & 3,172 & 3,086 & 2,821 \\
& 0.027 & 0.046 & 0.059 & 0.065 & 0.048 & 0.018 & 0.142 \\
\hline GBR & 1,305 & 1,020 & 1,084 & 1,266 & 862 & 614 & 567 \\
& 0.041 & 0.063 & 0.069 & 0.072 & 0.046 & 0.059 & -0.004 \\
\hline JPN & 2,140 & 2,095 & 2,025 & 1,953 & 1,581 & 1,401 & 2,101 \\
& 0.005 & 0.013 & 0.015 & 0.020 & 0.020 & 0.023 & 0.021 \\
\hline USA & 1,403 & 1,326 & 1,018 & 960 & 861 & 905 & 639 \\
& -0.022 & 0.027 & 0.033 & 0.035 & 0.038 & 0.038 & 0.012 \\
\hline \hline
\end{tabular}

\begin{tabular}{||l|ccccccc||}
\hline \multirow{2}{*}{} & \multicolumn{7}{|c||}{$\begin{array}{c}\text { Average Returns (upper) } \\
\text { Standard Deviation of Returns (lower) }\end{array}$} \\
\hline Country & Low-1 & $\mathbf{2}$ & $\mathbf{3}$ & $\mathbf{4}$ & $\mathbf{5}$ & $\mathbf{6}$ & High-7 \\
\hline AUS & $9.6 \%$ & $13.2 \%$ & $19.6 \%$ & $18.8 \%$ & $14.6 \%$ & $19.3 \%$ & $32.1 \%$ \\
& 0.70 & 0.62 & 0.59 & 0.51 & 0.56 & 0.64 & 0.70 \\
\hline CAN & $12.0 \%$ & $11.6 \%$ & $16.4 \%$ & $16.1 \%$ & $18.4 \%$ & $16.2 \%$ & $30.2 \%$ \\
& 0.65 & 0.49 & 0.47 & 0.44 & 0.42 & 0.45 & 0.75 \\
\hline FRA & $13.3 \%$ & $9.7 \%$ & $13.0 \%$ & $15.5 \%$ & $12.1 \%$ & $17.4 \%$ & $24.0 \%$ \\
& 0.53 & 0.65 & 0.65 & 0.64 & 0.61 & 0.60 & 0.74 \\
\hline DEU & $8.5 \%$ & $13.3 \%$ & $13.6 \%$ & $20.3 \%$ & $21.2 \%$ & $16.5 \%$ & $25.7 \%$ \\
& 0.68 & 0.70 & 0.70 & 0.71 & 0.73 & 0.74 & 0.77 \\
\hline GBR & $10.1 \%$ & $16.3 \%$ & $19.4 \%$ & $21.2 \%$ & $20.0 \%$ & $21.1 \%$ & $23.2 \%$ \\
& 0.63 & 0.64 & 0.65 & 0.68 & 0.72 & 0.64 & 0.62 \\
\hline JPN & $6.0 \%$ & $10.4 \%$ & $11.2 \%$ & $13.0 \%$ & $14.2 \%$ & $15.1 \%$ & $19.8 \%$ \\
& 1.02 & 0.97 & 0.95 & 0.94 & 0.90 & 0.90 & 0.91 \\
\hline USA & $14.7 \%$ & $16.2 \%$ & $16.6 \%$ & $18.0 \%$ & $18.6 \%$ & $18.3 \%$ & $24.8 \%$ \\
& 0.66 & 0.59 & 0.58 & 0.54 & 0.51 & 0.46 & 0.48 \\
\hline
\end{tabular}

\begin{tabular}{||l|ccccccc||}
\hline \multirow{2}{*}{} & \multicolumn{7}{|c|}{$\begin{array}{c}\text { Market Portfolio Betas (upper) } \\
\text { Sharpe Ratios (lower) }\end{array}$} \\
& \multicolumn{7}{|c}{ and } \\
\hline Country & Low-1 & $\mathbf{2}$ & $\mathbf{3}$ & $\mathbf{4}$ & $\mathbf{5}$ & $\mathbf{6}$ & High-7 \\
\hline AUS & 0.87 & 0.96 & 0.82 & 0.76 & 0.67 & 0.85 & 0.86 \\
& -0.045 & -0.024 & 0.048 & 0.074 & 0.007 & 0.046 & 0.189 \\
\hline CAN & 1.02 & 0.90 & 0.91 & 0.85 & 0.79 & 0.81 & 0.95 \\
& 0.016 & 0.016 & 0.102 & 0.104 & 0.151 & 0.114 & 0.244 \\
\hline FRA & 0.67 & 0.79 & 0.75 & 0.83 & 0.79 & 0.78 & 0.79 \\
& 0.052 & -0.006 & 0.032 & 0.061 & 0.018 & 0.088 & 0.177 \\
\hline DEU & 0.90 & 0.94 & 0.95 & 0.91 & 0.92 & 0.94 & 0.92 \\
& -0.047 & 0.018 & 0.018 & 0.108 & 0.111 & 0.044 & 0.155 \\
\hline GBR & 0.95 & 0.98 & 0.98 & 1.00 & 1.02 & 0.96 & 0.92 \\
& -0.067 & 0.023 & 0.059 & 0.088 & 0.067 & 0.094 & 0.123 \\
\hline JPN & 1.06 & 1.02 & 1.00 & 0.98 & 0.93 & 0.92 & 0.89 \\
& 0.005 & 0.049 & 0.059 & 0.077 & 0.099 & 0.108 & 0.161 \\
\hline USA & 1.19 & 1.15 & 1.15 & 1.03 & 0.99 & 0.87 & 0.84 \\
& 0.067 & 0.100 & 0.108 & 0.141 & 0.165 & 0.185 & 0.291 \\
\hline \hline
\end{tabular}


PANEL B ${ }^{1}$

Sorted by Market Value

\begin{tabular}{|c|c|c|c|c|c|c|c|}
\hline \multirow[b]{2}{*}{ Country } & \multicolumn{7}{|c|}{$\begin{array}{c}\text { Market Value }^{2} \text { (upper) and } \\
\text { Number of Firms (lower) }\end{array}$} \\
\hline & Low-1 & 2 & 3 & 4 & 5 & 6 & High-7 \\
\hline AUS & $\begin{array}{l}53 \\
20\end{array}$ & $\begin{array}{c}107 \\
20\end{array}$ & $\begin{array}{c}169 \\
20\end{array}$ & $\begin{array}{c}256 \\
19\end{array}$ & $\begin{array}{c}446 \\
19\end{array}$ & $\begin{array}{c}857 \\
19\end{array}$ & $\begin{array}{c}2,958 \\
19\end{array}$ \\
\hline CAN & \begin{tabular}{|l}
14 \\
47 \\
\end{tabular} & $\begin{array}{l}40 \\
47 \\
\end{array}$ & $\begin{array}{l}73 \\
47 \\
\end{array}$ & $\begin{array}{c}127 \\
46 \\
\end{array}$ & $\begin{array}{c}223 \\
46 \\
\end{array}$ & $\begin{array}{c}447 \\
46 \\
\end{array}$ & $\begin{array}{c}1,828 \\
46\end{array}$ \\
\hline FRA & $\begin{array}{l}33 \\
13\end{array}$ & $\begin{array}{l}73 \\
13\end{array}$ & $\begin{array}{c}126 \\
13\end{array}$ & $\begin{array}{c}202 \\
13\end{array}$ & $\begin{array}{c}335 \\
12\end{array}$ & $\begin{array}{c}602 \\
12\end{array}$ & $\begin{array}{c}2,381 \\
12\end{array}$ \\
\hline$\overline{\mathrm{DEU}}$ & \begin{tabular}{|c|}
273 \\
21 \\
\end{tabular} & $\begin{array}{c}674 \\
21 \\
\end{array}$ & $\begin{array}{c}1,119 \\
21\end{array}$ & $\begin{array}{c}1,706 \\
20\end{array}$ & $\begin{array}{c}2,532 \\
20\end{array}$ & $\begin{array}{c}4,190 \\
20\end{array}$ & $\begin{array}{c}14,783 \\
20\end{array}$ \\
\hline$\overline{\text { GBR }}$ & $\begin{array}{l}38 \\
93 \\
\end{array}$ & $\begin{array}{l}79 \\
93 \\
\end{array}$ & $\begin{array}{c}133 \\
93 \\
\end{array}$ & $\begin{array}{c}218 \\
93 \\
\end{array}$ & $\begin{array}{c}383 \\
93 \\
\end{array}$ & $\begin{array}{c}844 \\
93 \\
\end{array}$ & $\begin{array}{c}4,953 \\
92 \\
\end{array}$ \\
\hline JPN & $\begin{array}{l}187 \\
151\end{array}$ & $\begin{array}{l}321 \\
151\end{array}$ & $\begin{array}{l}476 \\
151\end{array}$ & $\begin{array}{l}718 \\
151\end{array}$ & $\begin{array}{c}1,147 \\
151\end{array}$ & $\begin{array}{c}2,088 \\
151\end{array}$ & $\begin{array}{c}8,395 \\
151\end{array}$ \\
\hline USA & $\begin{array}{c}12 \\
333\end{array}$ & $\begin{array}{c}37 \\
333\end{array}$ & $\begin{array}{c}78 \\
332\end{array}$ & $\begin{array}{l}151 \\
332\end{array}$ & $\begin{array}{l}317 \\
332\end{array}$ & $\begin{array}{l}813 \\
332\end{array}$ & $\begin{array}{c}5,532 \\
332\end{array}$ \\
\hline
\end{tabular}

\begin{tabular}{||l|ccccccc||}
\hline \hline & \multicolumn{7}{|c||}{$\begin{array}{c}\text { Book-to Market Ratios (upper) and } \\
\text { Earnings to Price Ratio (lower) }\end{array}$} \\
\hline Country & Low-1 & $\mathbf{2}$ & $\mathbf{3}$ & $\mathbf{4}$ & $\mathbf{5}$ & $\mathbf{6}$ & High-7 \\
\hline AUS & 1.218 & 1.034 & 0.900 & 0.803 & 0.813 & 0.644 & 0.658 \\
& -0.671 & -0.043 & 0.042 & 0.073 & 0.073 & 0.074 & 0.070 \\
\hline CAN & 0.502 & 0.972 & 0.906 & 0.887 & 0.828 & 0.825 & 0.777 \\
& 0.708 & -0.016 & -0.007 & 0.047 & 0.021 & 0.032 & 0.057 \\
\hline FRA & 0.553 & 0.654 & 0.594 & 0.588 & 0.641 & 0.553 & 0.833 \\
& -0.028 & 0.006 & 0.018 & 0.027 & 0.043 & 0.029 & 0.062 \\
\hline DEU & 0.495 & 0.719 & 0.571 & 0.533 & 0.831 & 0.522 & 0.548 \\
& -0.009 & 0.020 & 0.061 & 0.049 & 0.094 & 0.077 & 0.076 \\
\hline GBR & 0.809 & 0.744 & 0.710 & 0.699 & 0.680 & 0.645 & 0.586 \\
& -0.158 & 0.028 & 0.056 & 0.064 & 0.060 & 0.068 & 0.075 \\
\hline JPN & 0.386 & 0.416 & 0.403 & 0.399 & 0.384 & 0.382 & 0.348 \\
& 0.008 & 0.014 & 0.015 & 0.018 & 0.018 & 0.020 & 0.021 \\
\hline USA & 0.523 & 0.733 & 0.762 & 0.659 & 0.662 & 0.683 & 0.707 \\
& -0.453 & -0.050 & -0.003 & 0.036 & 0.056 & 0.061 & 0.077 \\
\hline \hline
\end{tabular}

\begin{tabular}{||l|ccccccc||}
\hline \multirow{5}{*}{} & \multicolumn{7}{|c||}{ Average Returns (upper) and } \\
& \multicolumn{7}{|c||}{ Standard Deviation of Returns (lower) } \\
\hline Country & Low-1 & $\mathbf{2}$ & $\mathbf{3}$ & $\mathbf{4}$ & $\mathbf{5}$ & $\mathbf{6}$ & High-7 \\
\hline AUS & $30.4 \%$ & $17.8 \%$ & $11.1 \%$ & $15.6 \%$ & $16.6 \%$ & $18.9 \%$ & $18.6 \%$ \\
& 1.01 & 0.57 & 0.57 & 0.53 & 0.53 & 0.63 & 0.62 \\
\hline CAN & $44.3 \%$ & $20.3 \%$ & $12.5 \%$ & $11.9 \%$ & $9.3 \%$ & $11.1 \%$ & $8.6 \%$ \\
& 0.97 & 0.52 & 0.49 & 0.45 & 0.46 & 0.46 & 0.45 \\
\hline FRA & $17.5 \%$ & $13.2 \%$ & $15.0 \%$ & $13.9 \%$ & $17.9 \%$ & $11.2 \%$ & $13.8 \%$ \\
& 0.66 & 0.73 & 0.70 & 0.63 & 0.52 & 0.59 & 0.70 \\
\hline DEU & $26.6 \%$ & $19.7 \%$ & $15.5 \%$ & $12.4 \%$ & $14.5 \%$ & $14.8 \%$ & $12.6 \%$ \\
& 0.94 & 0.73 & 0.63 & 0.72 & 0.71 & 0.75 & 0.65 \\
\hline GBR & $22.2 \%$ & $18.8 \%$ & $18.8 \%$ & $16.9 \%$ & $17.5 \%$ & $17.4 \%$ & $18.4 \%$ \\
& 0.78 & 0.67 & 0.69 & 0.67 & 0.67 & 0.67 & 0.61 \\
\hline JPN & $21.5 \%$ & $16.3 \%$ & $13.6 \%$ & $12.9 \%$ & $10.6 \%$ & $8.9 \%$ & $5.7 \%$ \\
& 1.12 & 1.00 & 1.00 & 0.98 & 0.94 & 0.88 & 0.78 \\
\hline USA & $47.3 \%$ & $18.0 \%$ & $16.0 \%$ & $15.7 \%$ & $15.7 \%$ & $16.2 \%$ & $16.7 \%$ \\
& 1.38 & 0.60 & 0.56 & 0.58 & 0.58 & 0.52 & 0.48 \\
\hline \hline
\end{tabular}

\begin{tabular}{||l|ccccccc||}
\hline \multirow{2}{*}{} & \multicolumn{7}{|c|}{$\begin{array}{c}\text { Market Portfolio Betas (upper) } \\
\text { Sharpe Ratios (lower) }\end{array}$} \\
& \multicolumn{7}{|c}{ and } \\
\hline Country & Low-1 & $\mathbf{2}$ & $\mathbf{3}$ & $\mathbf{4}$ & $\mathbf{5}$ & $\mathbf{6}$ & High-7 \\
\hline AUS & 0.84 & 0.73 & 0.76 & 0.69 & 0.79 & 0.91 & 1.08 \\
& 0.141 & 0.045 & -0.042 & 0.014 & 0.039 & 0.042 & 0.032 \\
\hline CAN & 1.00 & 0.87 & 0.87 & 0.82 & 0.91 & 0.95 & 0.95 \\
& 0.312 & 0.151 & 0.036 & 0.030 & -0.017 & 0.009 & -0.028 \\
\hline FRA & 0.62 & 0.78 & 0.82 & 0.76 & 0.67 & 0.78 & 0.96 \\
& 0.104 & 0.030 & 0.057 & 0.053 & 0.110 & 0.006 & 0.039 \\
\hline DEU & 1.01 & 0.91 & 0.80 & 0.92 & 0.94 & 1.01 & 0.90 \\
& 0.131 & 0.101 & 0.050 & 0.002 & 0.032 & 0.028 & 0.008 \\
\hline GBR & 0.91 & 0.87 & 0.94 & 0.99 & 1.03 & 1.08 & 1.02 \\
& 0.096 & 0.053 & 0.057 & 0.031 & 0.034 & 0.034 & 0.054 \\
\hline JPN & 1.00 & 0.95 & 0.97 & 0.99 & 1.00 & 0.98 & 0.93 \\
& 0.153 & 0.108 & 0.082 & 0.073 & 0.050 & 0.038 & 0.002 \\
\hline USA & 1.02 & 0.98 & 1.04 & 1.11 & 1.12 & 1.08 & 1.02 \\
& 0.265 & 0.128 & 0.102 & 0.095 & 0.098 & 0.124 & 0.149 \\
\hline \hline
\end{tabular}

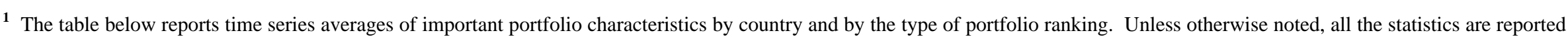
in local currency. All balance sheet data come from balance sheets reported no later than April of year t. These statistics are first calculated for the individual firm at year $t$, and are equally weighted into the portfolio in which it belongs at that date. Time series averages are for each portfolio as a whole. The sample period for USA and CAN is November 1983 to October 1994 and for AUS, FRA, DEU, GBR, and JPN is November 1986 to October 1994.

2 The Market Values are reported in millions of US\$s, translated at the average exchange rate for the period. 


\section{TABLE 2: The Relation Between Jensen's Alphas and Market Value and Book-to-Market}

Panels A and B show the rank correlations of returns of portfolios with the ranking variables, for each country. A value of 1.00 means that the portfolio returns increase monotonically with their ranking.

Panel C shows estimates of Jensen's alphas when the pricing model includes only the market portfolio and when it also includes the BE/ME HML portfolio. The 7 portfolios are constructed by converting the corresponding country portfolios into U.S.\$ returns and weighting them equally. P-values for the hypothesis that the coefficient is not different from zero are in parentheses.

PANEL A

Average Returns

\begin{tabular}{||l|cc||}
\hline & \multicolumn{2}{|c||}{ Rank Correlations } \\
& $\boldsymbol{B E} / \boldsymbol{M E}$ & $\boldsymbol{M V E}$ \\
\hline Australia & 0.71 & 0.18 \\
Canada & 0.89 & 0.96 \\
Germany & 0.64 & 0.46 \\
France & 0.89 & 0.79 \\
U.K. & 0.96 & 0.64 \\
Japan & 1.00 & 1.00 \\
USA & 0.96 & 0.39 \\
\hline
\end{tabular}

PANEL B

Zero-beta Returns

\begin{tabular}{|c|c|c|c|c|}
\hline & \multicolumn{2}{|c|}{ Rank Correlations } & \multicolumn{2}{|c|}{$\begin{array}{l}\text { P-Values of } \\
\text { Wald Tests }\end{array}$} \\
\hline & $B E / M E$ & $M V E$ & $B E / M E$ & MVE \\
\hline Australia & 0.68 & 0.50 & 0.009 & 0.575 \\
\hline Canada & 0.96 & 0.96 & 0.003 & 0.000 \\
\hline ||Germany & 0.64 & 0.50 & 0.103 & 0.274 \\
\hline France & 0.89 & 0.75 & 0.002 & 0.281 \\
\hline U.K. & 0.96 & 0.75 & 0.000 & 0.491 \\
\hline Japan & 1.00 & 1.00 & 0.017 & 0.162 \\
\hline USA & 1.00 & 0.68 & 0.000 & 0.029 \\
\hline
\end{tabular}


PANEL C

Jensen's Alphas with and without the HML Portfolio

\begin{tabular}{|c|c|c|c|c|c|c|c|}
\hline \multirow{2}{*}{\begin{tabular}{||l} 
BE/ME-Sorted \\
Portfolios
\end{tabular}} & \multicolumn{6}{|l|}{ Low } & $\mathbf{H i}$ \\
\hline & 1 & 2 & 3 & 4 & 5 & 6 & 7 \\
\hline Without HML & $\begin{array}{c}-0.009 \\
(0.751)\end{array}$ & $\begin{array}{c}0.010 \\
(0.713)\end{array}$ & $\begin{array}{c}0.036 \\
(0.160)\end{array}$ & $\begin{array}{c}0.062 \\
(0.028)\end{array}$ & $\begin{array}{c}0.053 \\
(0.061)\end{array}$ & $\begin{array}{c}0.061 \\
(0.031)\end{array}$ & $\begin{array}{c}0.146 \\
(0.000)\end{array}$ \\
\hline With HML & $\begin{array}{c}-0.012 \\
(0.734) \\
\end{array}$ & $\begin{array}{l}-0.001 \\
(0.987) \\
\end{array}$ & $\begin{array}{c}0.004 \\
(0.888) \\
\end{array}$ & $\begin{array}{c}0.015 \\
(0.659) \\
\end{array}$ & $\begin{array}{c}-0.014 \\
(0.655) \\
\end{array}$ & $\begin{array}{c}-0.025 \\
(0.422) \\
\end{array}$ & $\begin{array}{c}0.013 \\
(0.724) \\
\end{array}$ \\
\hline & Small & & & & & & Large \\
\hline \begin{tabular}{|l}
$M V E-S o r t e d$ \\
Portfolios
\end{tabular} & 1 & 2 & 3 & 4 & 5 & 6 & 7 \\
\hline Without HML & $\begin{array}{c}0.198 \\
(0.000)\end{array}$ & $\begin{array}{c}0.063 \\
(0.063)\end{array}$ & $\begin{array}{c}0.032 \\
(0.278)\end{array}$ & $\begin{array}{c}0.023 \\
(0.397)\end{array}$ & $\begin{array}{c}0.031 \\
(0.245)\end{array}$ & $\begin{array}{c}0.018 \\
(0.502)\end{array}$ & $\begin{array}{c}0.016 \\
(0.487)\end{array}$ \\
\hline With HML & $\begin{array}{c}0.048 \\
(0.358)\end{array}$ & $\begin{array}{l}-0.016 \\
(0.676)\end{array}$ & $\begin{array}{l}-0.020 \\
(0.567)\end{array}$ & $\begin{array}{l}-0.022 \\
(0.505)\end{array}$ & $\begin{array}{c}-0.002 \\
(0.938)\end{array}$ & $\begin{array}{l}-0.015 \\
(0.644)\end{array}$ & $\begin{array}{c}0.008 \\
(0.768)\end{array}$ \\
\hline
\end{tabular}




\section{NOTES FOR TABLE 3: Volatility Bounds - Unconditional Spanning Tests}

$R_{t}$ is a $n$ dimensional vector of date $t$ returns on $n$ assets; $r_{t}=R_{t}-E\left(R_{t}\right)$ is the vector of demeaned returns. The first $p$ of the $n$ assets are the reference assets and the remaining $q=n-p$ are the test assets. The returns are $R_{t}=\left(R_{p, t}^{\prime}, R_{q, t}^{\prime}\right)^{\prime}$. The SDF is $m_{c}$ and $c_{j}$ is the predetermined risk-free rate. We use two risk-free rates for the tests. If the $n$ assets are spanned by the reference assets, then the volatility bound constructed from the reference assets remains unchanged when the test assets are added. The time-invariant volatility bound is formed by constructing two discount factors that have expected values $c_{1}$ and $c_{2}$. The system that defines the volatility bound for $n$ assets is:

$$
R_{t}-E\left(R_{t} \mid m_{c_{j}}\right)=v_{j, t} E\left(\varepsilon_{\mathrm{t}}\right)=0, \text { and } \varepsilon_{\mathrm{t}}^{\prime}=\left(v_{l, t}^{\prime} v_{l, t}^{\prime}\right)
$$

where, $\quad E\left(R_{t} \mid m_{c_{j}}\right)=\left[1_{n}-\operatorname{Cov}\left(R_{t}, m_{c_{j}, t}\right)\right] / c_{j}$, and $m_{c_{j}, t}=\sum_{p=1}^{5(7)} \beta_{p, j} r_{p, t}+\sum_{q=6(8)}^{7(9)} \beta_{q, j} r_{q, t}+c_{j}$, for $j=1,2$.

The hypothesis that $p$ reference assets are sufficient to span $n$ assets implies that $\beta_{q, 1}=\beta_{q, 2}=0$; the $q$ test assets are not needed for pricing. Unconditional spanning implies the null hypothesis that $E\left(\varepsilon_{t}\right)=0$, i.e., returns are on average correctly priced. Iterated GMM is used to estimate the discount factor parameters $\beta_{p, 1}$, and $\beta_{p, 2}$, and the Hansen J-statistic is used to evaluate the overidentifying conditions implied by spanning. This test statistic is distributed $\chi^{2}$ with degrees of freedom equal to the number of overidentifying conditions. There are $2 n$ conditions and $2 p$ parameters, which leaves $2 q$ overidentifying conditions.

Seven $B E / M E$ - and $M V E$-sorted portfolios from each country, and 9 portfolios from 2-way rankings (by $M V E$ and then by $B E / M E$ ) are used for the spanning tests. The construction of $B E / M E, M V E$, and the portfolios is described in the Data section. Three tests are reported for each set of sorted portfolios for each country, each for a different pair of test assets.

The table shows the right hand tail probabilities for the unconditional spanning tests. Tests are based on GMM criteria at convergence or the tenth iteration, whichever was first. The GMM estimates are robust to firstorder autocorrelation and heteroskedasticity. The sample period is $11 / 83-10 / 94(\mathrm{~T}=132)$ in the USA and CAN, and 11/86 - 10/94 (T=96) in AUS, DEU, FRA, GBR, and JPN. Shaded entries are significant at the 5\% level. 
TABLE 3: Volatility Bounds - Unconditional Spanning Tests

J-Statistic P-Values

\begin{tabular}{|c|c|c|c|c|}
\hline \multirow[b]{2}{*}{ Country } & \multirow{2}{*}{$\begin{array}{l}\text { Portfolios } \\
\text { Sorted By }\end{array}$} & \multicolumn{3}{|c|}{ Test Portfolios } \\
\hline & & $1 \& 7$ & $2 \& 6$ & $3 \& 5$ \\
\hline AUS & \multirow{7}{*}{$B E / M E$} & 0.083 & 0.519 & 0.055 \\
\hline CAN & & 0.000 & 0.014 & 0.030 \\
\hline DEU & & 0.005 & 0.254 & 0.090 \\
\hline FRA & & 0.015 & 0.739 & 0.937 \\
\hline GBR & & 0.000 & 0.131 & 0.000 \\
\hline JPN & & 0.017 & 0.333 & 0.045 \\
\hline USA & & 0.000 & 0.000 & 0.684 \\
\hline AUS & \multirow{7}{*}{$M V E$} & 0.202 & 0.671 & 0.070 \\
\hline CAN & & 0.058 & 0.136 & 0.683 \\
\hline DEU & & 0.308 & 0.004 & 0.008 \\
\hline FRA & & 0.208 & 0.390 & 0.054 \\
\hline GBR & & 0.001 & 0.001 & 0.993 \\
\hline JPN & & 0.003 & 0.093 & 0.514 \\
\hline \multirow[t]{3}{*}{ USA } & & 0.000 & 0.632 & 0.147 \\
\hline & & \multicolumn{3}{|c|}{ Test Portfolios } \\
\hline & & $3 \& 7$ & $1 \& 9$ & $2 \& 6$ \\
\hline AUS & & 0.011 & 0.155 & 0.058 \\
\hline CAN & 2 way & 0.379 & 0.011 & 0.049 \\
\hline DEU & $M V E \&$ & 0.180 & 0.001 & 0.176 \\
\hline FRA & $B E / M E$ & 0.046 & 0.816 & 0.934 \\
\hline GBR & & 0.001 & 0.047 & 0.120 \\
\hline JPN & & 0.001 & 0.247 & 0.070 \\
\hline USA & & 0.000 & 0.001 & 0.276 \\
\hline
\end{tabular}




\section{NOTES FOR TABLE 4: \\ Conditional Spanning Tests with Time-varying SDFs using $B E / M E$ and $M V E$ as instruments.}

Panel $\boldsymbol{A}$ reports right hand tail probabilities of the null hypothesis that $\theta_{i, j}=0 \forall I, j$, jointly, i.e., the coefficients associated with $B E / M E$ or $M V E, \theta_{i} \mathrm{~s}$, are statistically significant. Let $R_{t}$ and $Z_{s, t-l}$ be $n$-dimensional vectors, respectively, of date $t$ returns on $n$ assets and $n$ portfolio specific conditioning variables, $s=B E / M E$ or $M V E$, one at a time. The system that defines the volatility bound for the $n$ assets is,

$$
\begin{aligned}
& R_{t}-E\left(R_{t} \mid m_{c_{1}}\right)=v_{1, t}, ; \quad E\left(\varepsilon_{t}\right)=0, E\left(\varepsilon_{t} \oplus Z_{s, t-1}\right)=0, \text { where } \varepsilon_{t}=\left(v_{1, t}^{\prime} v_{2, t}^{\prime}\right)^{\prime}, \\
& R_{t}-E\left(R_{t} \mid m_{c_{2}}\right)=v_{2, t},
\end{aligned}
$$

where $\oplus$ represents the Hadamard product. The SDF is,

$$
m_{c_{j}, t}=\sum_{i=1}^{7(9)}\left(\beta_{i, j}+\theta_{i, j} Z_{s, i, t-1}\right) r_{i, t}+c_{j} ; j=1,2, E\left(m_{c_{j}, t}\right)=c_{j}, \quad E\left(m_{c_{i}}, t\right)=c_{j}
$$

where $s=B E / M E, M V E$, and $r_{t}=R_{t}-E\left(R_{t}\right)$. To test the null hypothesis that $\left(\theta_{I}=0\right)$ in the augmented SDF we use the Wald test; the statistic is $\chi^{2}$-distributed where the degrees of freedom are the number of overidentifying restrictions $(2 n)$.

Panel $\boldsymbol{B}$ reports right hand tail probabilities from Hansen J-tests of conditional spanning, using $B E / M E$ and $M V E$ as conditioning information. Different pairs of assets which are designated test assets $q$ and the remainder are designated reference assets $p ; n=q+p$. SDFs formed based only the reference assets (and the conditioning information) is asked to span (price) the test assets, within statistical tolerance. Analogous to the unconditional spanning case, the SDF is decomposed into the test assets and reference assets. The SDF is given by,

$$
m_{c_{j}, t}=\sum_{p=1}^{5(7)}\left(\beta_{p, j}+\theta_{p, j} Z_{s, p, t-1}\right) r_{p, t}+\sum_{q=6(8)}^{7(9)}\left(\beta_{q, j}+\theta_{q, j} Z_{s, q, t-1}\right) r_{q, t}+c_{j} ; \quad E\left(m_{c_{j}, t}\right)=c_{j} .
$$

The conditional spanning hypothesis ( $p$ reference assets are sufficient to span all $p+q=n$ assets) implies the parameter restrictions, $\beta_{q, 1}=\beta_{q, 2}=\theta_{q, 1}=\theta_{q, 2}=0$, since the $q$ test assets are excluded from the SDF. Conditional spanning implies that the average returns of all the assets are correctly priced. Thus we test the null hypothesis that the average pricing error is zero for all the assets. We use the Hansen J-statistic which is

$\chi^{2}$-distributed where the degrees of freedom are identical to those in the unconditional spanning case, and they are equal to $2 q$. Seven $B E / M E$ - and $M V E$-sorted portfolios from each country, and 9 portfolios from 2-way sorts (by $M V E$ and then by $B E / M E$ ) are used for the spanning tests. The construction of $B E / M E, M V E$, and the portfolios is described in the Data section. Three tests are reported for each set of sorts for each country, each for a different pair of test assets.

The GMM estimates are robust to first-order autocorrelation and heteroskedasticity. The sample period is $11 / 83$ - 10/94 ( $\mathrm{T}=132)$ in the USA and CAN, and 11/86 - 10/94 (T=96) in AUS, DEU, FRA, GBR, and JPN. Shaded entries are significant at the $5 \%$ level. 

TABLE 4: Time-Varying SDFs.

PANEL A

Joint Significance of the $B E / M E$ and $M V E$ Coefficients in the SDF

Wald Test P-Values

\begin{tabular}{|c|c|c|c|}
\hline Country & $\begin{array}{l}\text { Portfolios } \\
\text { Sorted by }\end{array}$ & $\begin{array}{c}\text { Conditional } \\
\text { on } B E / M E\end{array}$ & $\begin{array}{c}\text { Conditional } \\
\text { on } M V E\end{array}$ \\
\hline AUS & \multirow{7}{*}{$B E / M E$} & 0.000 & 0.000 \\
\hline CAN & & 0.000 & 0.013 \\
\hline DEU & & 0.006 & 0.001 \\
\hline FRA & & 0.000 & 0.000 \\
\hline GBR & & 0.000 & 0.002 \\
\hline JPN & & 0.001 & 0.000 \\
\hline USA & & 0.000 & 0.501 \\
\hline AUS & \multirow{7}{*}{$M V E$} & 0.000 & 0.000 \\
\hline CAN & & 0.000 & 0.000 \\
\hline DEU & & 0.242 & 0.002 \\
\hline FRA & & 0.000 & 0.270 \\
\hline GBR & & 0.000 & 0.002 \\
\hline JPN & & 0.031 & 0.000 \\
\hline USA & & 0.000 & 0.001 \\
\hline AUS & \multirow{7}{*}{$\begin{array}{c}2 \text { way } \\
M V E \& \\
B E / M E\end{array}$} & 0.000 & 0.000 \\
\hline CAN & & 0.006 & 0.068 \\
\hline DEU & & 0.005 & 0.000 \\
\hline FRA & & 0.000 & 0.000 \\
\hline GBR & & 0.000 & 0.000 \\
\hline JPN & & 0.005 & 0.000 \\
\hline USA & & 0.000 & 0.002 \\
\hline
\end{tabular}


PANEL B

Spanning Performance of Time-Varying SDFs

Instruments $=B E / M E, M V E$

J-Statistic Test P-Values

\begin{tabular}{|c|c|c|c|c|c|c|c|}
\hline \multirow[b]{3}{*}{ Country } & \multirow{3}{*}{$\begin{array}{l}\text { Portfolios } \\
\text { Sorted By }\end{array}$} & \multicolumn{6}{|c|}{ Instruments } \\
\hline & & \multicolumn{3}{|c|}{$\begin{array}{c}B E / M E \\
\text { Test Portfolios }\end{array}$} & \multicolumn{3}{|c|}{$\begin{array}{c}M V E \\
\text { Test Portfolios }\end{array}$} \\
\hline & & $1 \& 7$ & $2 \& 6$ & $3 \& 5$ & $1 \& 7$ & $2 \& 6$ & $3 \& 5$ \\
\hline AUS & \multirow{7}{*}{$B E / M E$} & 0.036 & 0.542 & 0.043 & 0.023 & 0.370 & 0.072 \\
\hline CAN & & 0.000 & 0.005 & 0.010 & 0.000 & 0.002 & 0.012 \\
\hline DEU & & 0.010 & 0.230 & 0.119 & 0.025 & 0.266 & 0.234 \\
\hline FRA & & 0.028 & 0.803 & 0.567 & 0.026 & 0.597 & 0.614 \\
\hline GBR & & 0.000 & 0.057 & 0.001 & 0.000 & 0.175 & 0.001 \\
\hline |JPN & & 0.007 & 0.384 & 0.076 & 0.010 & 0.557 & 0.136 \\
\hline USA & & 0.001 & 0.000 & 0.659 & 0.000 & 0.000 & 0.857 \\
\hline AUS & \multirow{7}{*}{$M V E$} & 0.071 & 0.440 & 0.054 & 0.009 & 0.296 & 0.074 \\
\hline CAN & & 0.006 & 0.033 & 0.673 & 0.007 & 0.082 & 0.462 \\
\hline DEU & & 0.443 & 0.007 & 0.002 & 0.840 & 0.011 & 0.015 \\
\hline FRA & & 0.289 & 0.618 & 0.199 & 0.201 & 0.312 & 0.084 \\
\hline GBR & & 0.001 & 0.008 & 0.978 & 0.006 & 0.018 & 0.878 \\
\hline |JPN & & 0.000 & 0.241 & 0.509 & 0.009 & 0.092 & 0.598 \\
\hline \multirow[t]{3}{*}{ USA } & & 0.000 & 0.755 & 0.149 & 0.000 & 0.790 & 0.213 \\
\hline & & \multicolumn{3}{|c|}{ Test Portfolios } & \multicolumn{3}{|c|}{ Test Portfolios } \\
\hline & & $3 \& 7$ & $1 \& 9$ & $2 \& 6$ & $3 \& 7$ & $1 \& 9$ & $2 \& 6$ \\
\hline AUS & \multirow{7}{*}{$\begin{array}{c}2 \text { way } \\
M V E \& \\
B E / M E\end{array}$} & 0.007 & 0.123 & 0.223 & 0.004 & 0.297 & 0.177 \\
\hline CAN & & 0.266 & 0.007 & 0.080 & 0.174 & 0.005 & 0.048 \\
\hline DEU & & 0.207 & 0.066 & 0.425 & 0.242 & 0.064 & 0.466 \\
\hline FRA & & 0.028 & 0.898 & 0.821 & 0.032 & 0.729 & 0.983 \\
\hline GBR & & 0.001 & 0.073 & 0.012 & 0.039 & 0.074 & 0.109 \\
\hline |JPN & & 0.003 & 0.018 & 0.054 & 0.044 & 0.100 & 0.230 \\
\hline USA & & 0.000 & 0.001 & 0.120 & 0.000 & 0.003 & 0.184 \\
\hline
\end{tabular}




\section{NOTES FOR TABLE 5:}

\section{Conditional Spanning Tests with Time-Varying SDFs Using $B E / M E$ and Several Other Instruments One-at-a-Time.}

Panel $A$ reports the number of instruments which, when included in the SDF along with the portfoliospecific $B E / M E$ s result in spanning, at the 5\% significance level. These data are reported for each country, for each of the 3 portfolio rankings we employ, and for three sets of test assets. The test assets are listed on the header of each column. 15 instruments are tested one at a time, so the score in these columns cannot exceed 15.

The right-hand column reports the "best performing" instrument for each country. We choose the best performing instrument by counting the number of instances in which each instrument enables the associated SDF to span the test assets, only when the test assets are the in-between pair of portfolios $(2 \& 6 / 1 \& 9)$ or the middle pair of portfolios $(3 \& 5 / 2 \& 6)$. We do not count the spanning performance for the extreme pair $(1 \& 7 / 3 \& 7)$ because spanning is rare in those cases.

The spanning test is very similar to that in Table 4 , and it is specified as follows:

Let $R_{t}$ and $Z_{t-1}$ are $n$-dimensional vectors, respectively, of date $t$ returns on $n$ assets and $n$ portfolio specific BE/MEs. Let $V_{k, t-l}$ be the $k^{\text {th }}$ of the 17 instruments to be considered. We require the pricing errors of each portfolio to be orthogonal to their own $B E / M E$ and to $V_{k}$. The system that defines the volatility bound for the $n$ assets is,

$$
\begin{aligned}
& R_{t}-E\left(R_{t} \mid m_{c_{1}}\right)=v_{1, t} \quad ; \quad E\left(\eta_{t}\right)=0, E\left(\varepsilon_{t} \oplus \boldsymbol{Z}\right)=0, E\left(\varepsilon_{t} \otimes \boldsymbol{V}_{k}\right)=0, \eta_{t}=\left(v_{1, t}^{\prime} v_{2, t}^{\prime}\right)^{\prime} . \\
& R_{t}-E\left(R_{t} \mid m_{c_{2}}\right)=v_{2, t}
\end{aligned}
$$

where $\oplus$ and $\otimes$ represent the Hadamard and Kroenecker products respectively. Different pairs of assets are designated as test assets $q$ and the remainder are designated reference assets $p ; n=q+p$. We evaluate the ability of the SDFs, formed only from the reference assets and the instruments, to span the test assets. The SDF is given by, $(4 \mathrm{c})$

$$
m_{c_{j}, t}=\sum_{p=1}^{5(7)}\left(\beta_{p, j}+\theta_{p, j} Z_{p, t-1}+\lambda_{p, j} V_{k, t-1}\right) r_{p, t}+\sum_{q=6(8)}^{7(9)}\left(\beta_{q, j}+\theta_{q, j} Z_{q, t-1}+\lambda_{q, j} V_{k, t-1}\right) r_{q, t}+c_{j} ; j=1,2 ; E\left(m_{c_{j}, t}\right)=c_{j},
$$

where, $Z_{i}=B E / M E_{i}$ of the various portfolios, and $r_{t}=R_{t}-E\left(R_{t}\right)$. The conditional spanning hypothesis ( $p$ reference assets are sufficient to span all $p+q=n$ assets) implies the parameter restrictions, $\beta_{q, 1}=\beta_{q, 2}=\theta_{q, 1}=\theta_{q, 2}=0$, since the $q$ test assets are excluded from the SDF. To test the null hypothesis, that average pricing error for all the portfolios is zero, we use the Hansen J-statistic on the constrained SDF; the statistic is $\chi^{2}$-distributed where the degrees of freedom is $2 q$, the number of test assets.

Seven $B E / M E$ - and $M V E$-sorted portfolios from each country, and 9 portfolios from 2-way sortings (by $M V E$ and then by $B E / M E$ ) are used for the spanning tests. The construction of $B E / M E, M V E$, and the portfolios is described in the Data section. Three tests are reported for each ranking for each country, each for a different set of test assets.

The GMM estimates are robust to first-order autocorrelation and heteroskedasticity. The sample period is $11 / 83-10 / 94(\mathrm{~T}=132)$ in the USA and CAN, and 11/86 - 10/94 $(\mathrm{T}=96)$ in AUS, DEU, FRA, GBR, and JPN.

Panel $B$ reports right hand tail probabilities from the above spanning test. The columns on the left report the spanning performance of WDIVPRE in addition to BE/ME. WDIVPRE is the overall best-performing instrument. The columns on the right report spanning performance of the "best" instrument for each country, when added to $B E / M E$. In selecting the "best" instrument we avoided choosing WDIVPRE whenever there was another equally well-performing instrument, in order to avoid duplication of results.

To enhance exposition, we report p-values only for the cells where spanning failed with $B E / M E$, but was achieved when the instrument was added to the SDF. Where spanning fails both with $B E / M E$ and $B E / M E$ and the instrument, we place “****. Where spanning was achieved already with $B E / M E$ we place "a.s.". 
TABLE 5: Spanning Performance of the Instruments (The SDF includes $B E / M E$ and the 15 instruments, one at a time)

PANEL A

Number of Instruments That Allow Spanning at the 5\% level.

\begin{tabular}{|c|c|c|c|c|c|}
\hline \multirow[b]{2}{*}{ Country } & \multirow{2}{*}{$\begin{array}{l}\text { Portfolios } \\
\text { Sorted By }\end{array}$} & \multicolumn{3}{|c|}{ Test Portfolios } & \multirow{2}{*}{$\begin{array}{l}\text { Best Performing } \\
\text { Instruments }{ }^{1}\end{array}$} \\
\hline & & $1 \& 7$ & $2 \& 6$ & $3 \& 5$ & \\
\hline AUS & \multirow{7}{*}{$B E / M E$} & 5 & 15 & 10 & \multirow{7}{*}{$\begin{array}{c}\text { WDIVPRE, GLINDP } \\
\text { LINFL } \\
\text { WDIVPRE, GLINDP } \\
\text { All } \\
\text { GLM2 } \\
\text { WDIVPRE, TPRE, LSTB } \\
\text { All but } \text { LINFL }\end{array}$} \\
\hline CAN & & 0 & 0 & 0 & \\
\hline DEU & & 0 & 13 & 12 & \\
\hline FRA & & 0 & 15 & 15 & \\
\hline GBR & & 0 & 8 & 0 & \\
\hline JPN & & 0 & 15 & 14 & \\
\hline USA & & 0 & 0 & 15 & \\
\hline AUS & \multirow{7}{*}{$M V E$} & 10 & 15 & 7 & \multirow{7}{*}{ same } \\
\hline CAN & & 0 & 11 & 15 & \\
\hline DEU & & 15 & 0 & 0 & \\
\hline FRA & & 14 & 15 & 15 & \\
\hline GBR & & 0 & 4 & 15 & \\
\hline JPN & & 0 & 14 & 15 & \\
\hline \multirow[t]{3}{*}{ USA } & & 0 & 15 & 15 & \\
\hline & \multicolumn{4}{|c|}{ Test Portfolios } & \\
\hline & & $3 \& 7$ & $1 \& 9$ & $2 \& 6$ & \\
\hline AUS & & 1 & 12 & 14 & \multirow{7}{*}{ same } \\
\hline CAN & 2 way & 14 & 1 & 11 & \\
\hline DEU & $M V E \&$ & 12 & 4 & 15 & \\
\hline FRA & $B E / M E$ & 2 & 15 & 15 & \\
\hline GBR & & 1 & 11 & 2 & \\
\hline JPN & & 2 & 6 & 12 & \\
\hline USA & & 0 & 0 & 14 & \\
\hline Average & & $3.6 / 15$ & $9.0 / 15$ & $11.0 / 15$ & \\
\hline
\end{tabular}

1 These are the instruments which most often result in the SDF spanning the test assets, when the tests portfolios are $2 \& 6 / 1 \& 9$ (in-between pair) and $3 \& 5 / 2 \& 6$ (middle pair). We do not take into account the spanning performance for test portfolios $1 \& 7 / 3 \& 7$ (extreme pair) because this pair is rarely spanned. 
PANEL B

Spanning Performance of WDIVPRE and the Best Performing Instrument for Each Country ${ }^{2}$ (BE/ME is included in all the SDFs)

J-Statistic Test P-Values

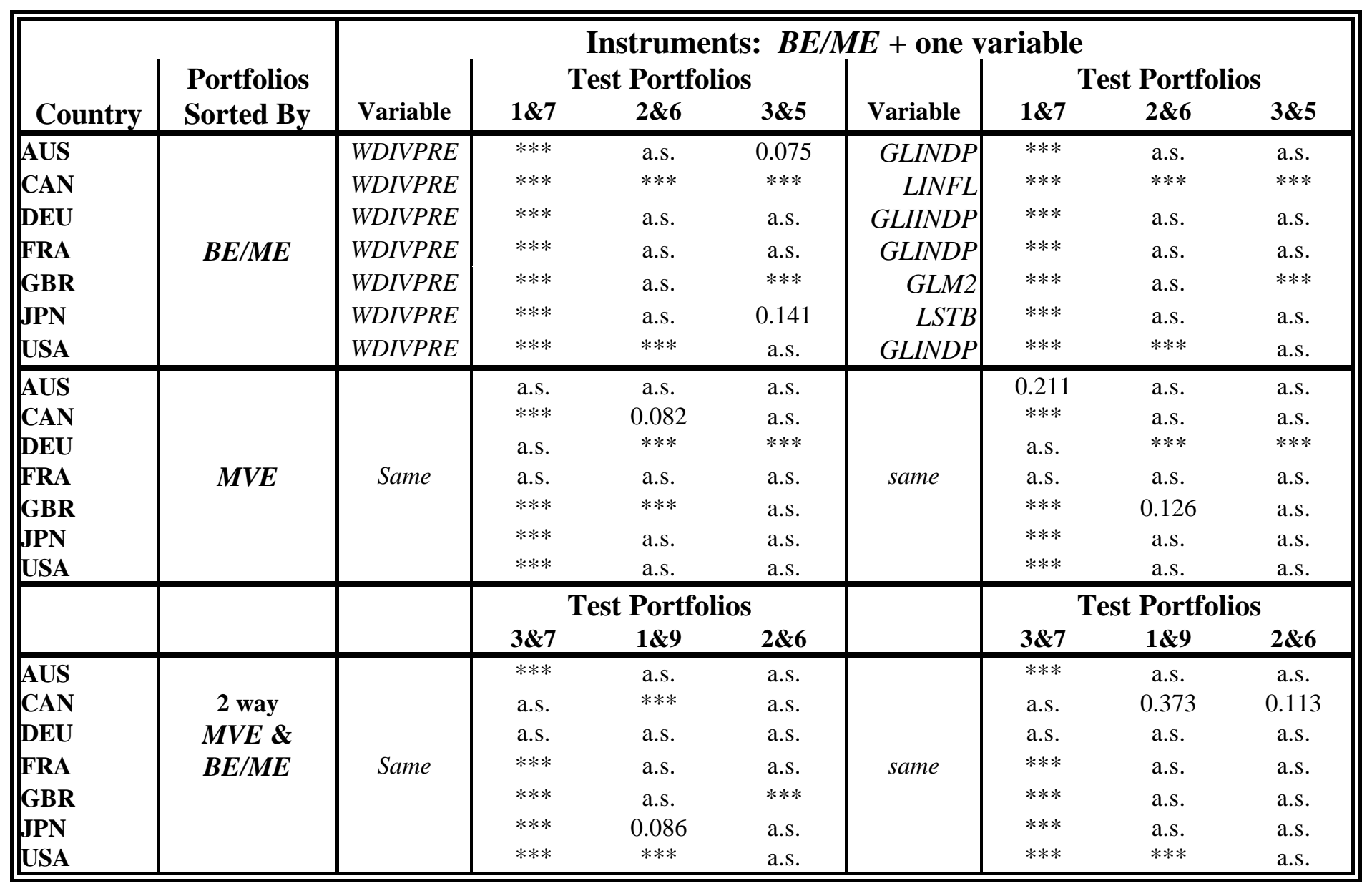

2 The best performing instrument is selected from the list in PANEL A. We chose instruments other than WDIVPRE whenever possible to avoid duplication with the first three columns. The designation “***”indicates that the combination was not spanned in Table 4 Panel B and it is still not, while "a.s." indicates that it is already spanned, in Table 4 Panel B. P-values are entered only when a cell was not spanned previously but is spanned now. 


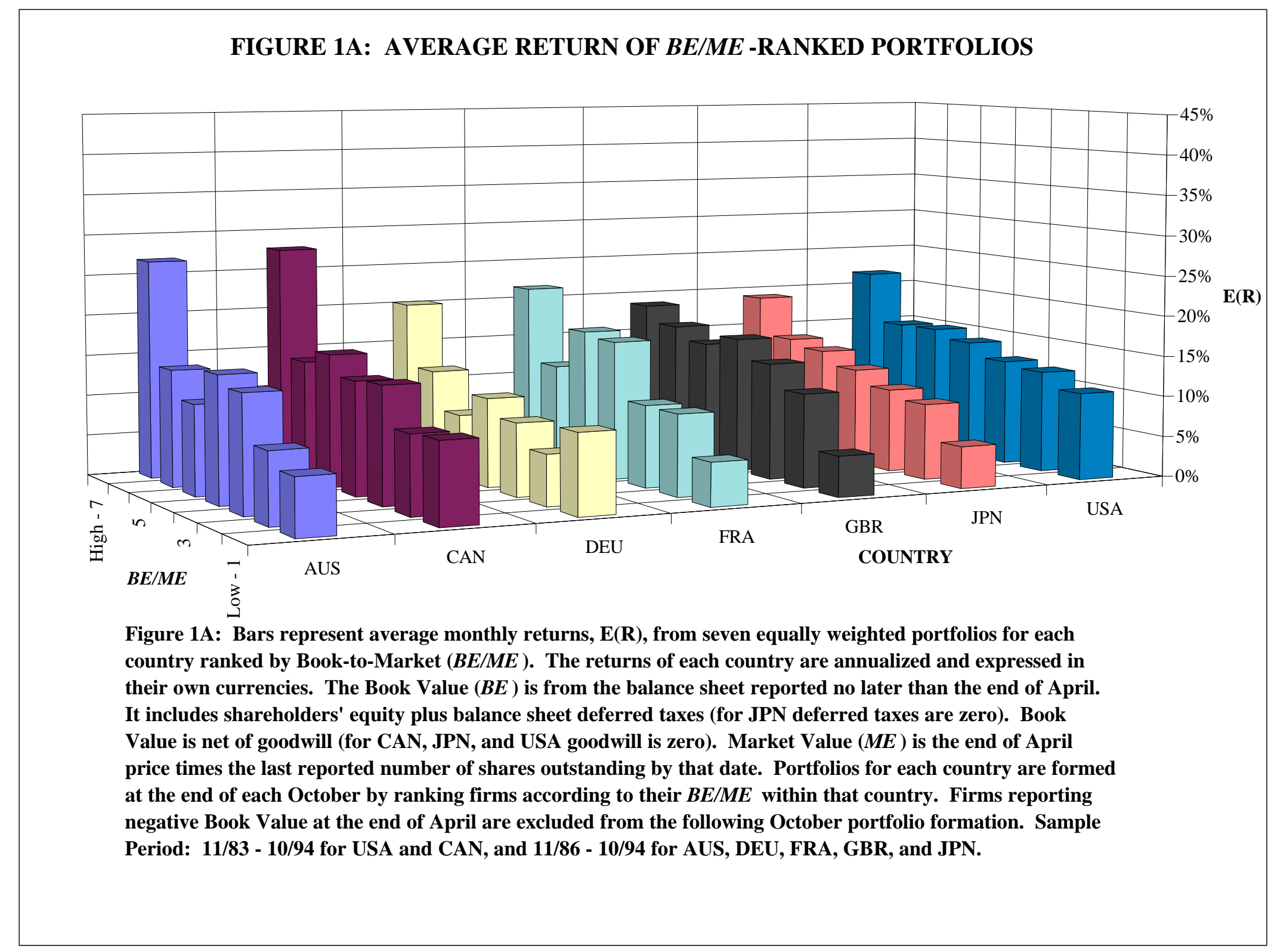




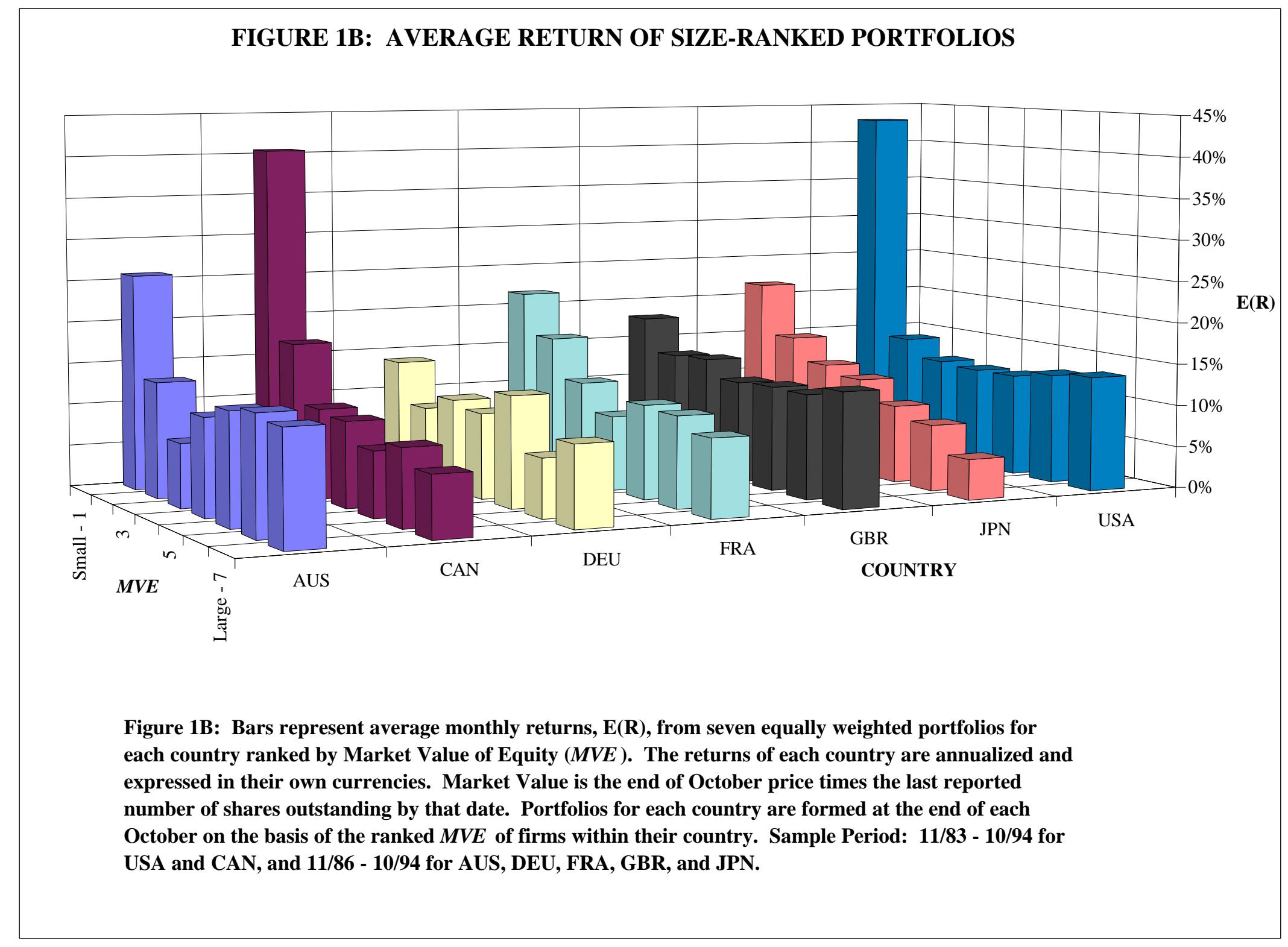




\section{FIGURE 2A: WORLD BETA OF BE/ME -RANKED PORTFOLIOS}

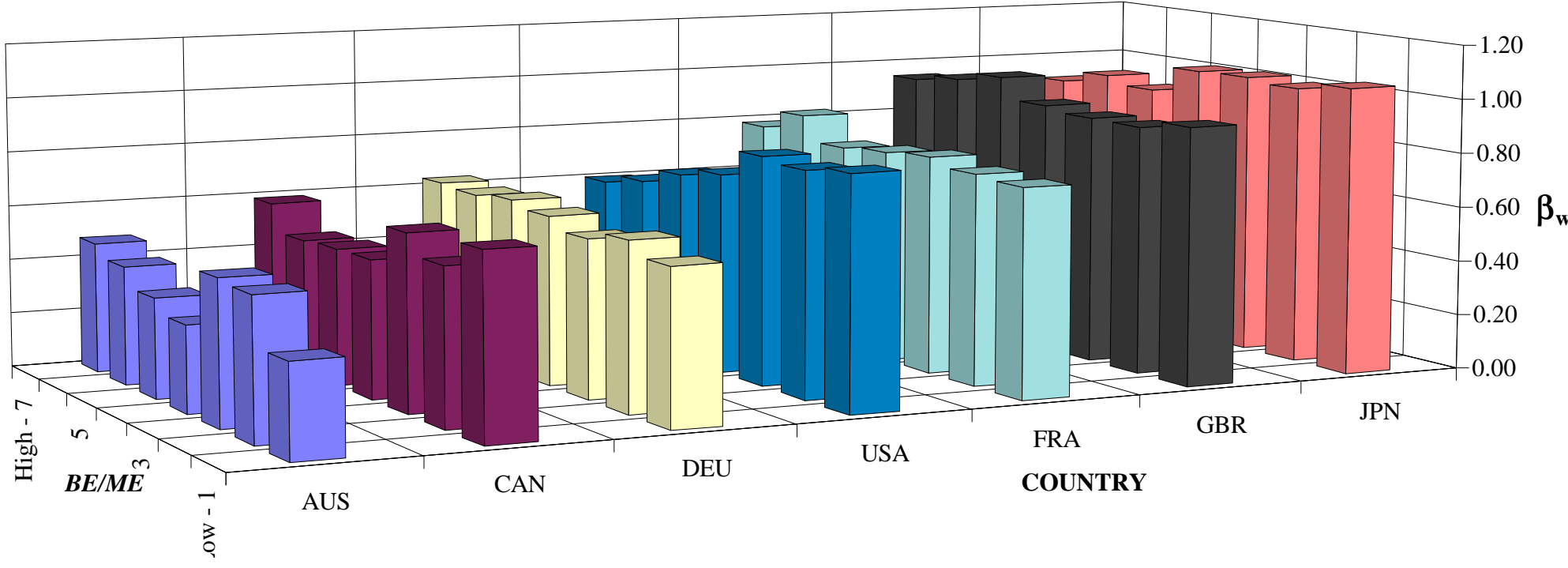

Figure 2A: Bars represent the World Market Betas $\left(\boldsymbol{\beta}_{w}\right)$ of seven equally weighted portfolios for each country ranked by Book-to-Market $(B E / M E)$. Betas are measured by the slope coefficients from a time series regression of monthly excess world returns on portfolio excess returns.

The world market return to each country is the MSCI world index return converted into local currency using the month-end closing rate. Portfolios for each country are formed at the end of each October on the basis of the ranked $B E / M E$ of firms within their country. The Book Value (BE) is from the balance sheet reported no later than the end of April. It includes shareholders' equity plus balance sheet deferred taxes (for JPN deferred taxes are zero). Book Value is net of goodwill (for CAN, JPN, and USA goodwill is zero). Firms reporting negative Book Value at the end of April are excluded from the following October portfolio formation. Market Value $(M E)$ is the end of April price times the last reported number of shares outstanding by that date. Excess returns are computed by subtracting from returns the applicable local one month risk-free rate or equivalent: AUS average rate on money market; CAN - one month Treasury Bill rate; FRA - call money rate; DEU - call money rate; GBR - one month Treasury Bill rate; JPN - call money rate; USA - one month Treasury Bill rate. Sample Period: 11/83 - 10/94 for USA and CAN, and 11/86 - 10/94 for AUS, DEU, FRA, GBR, and JPN. 


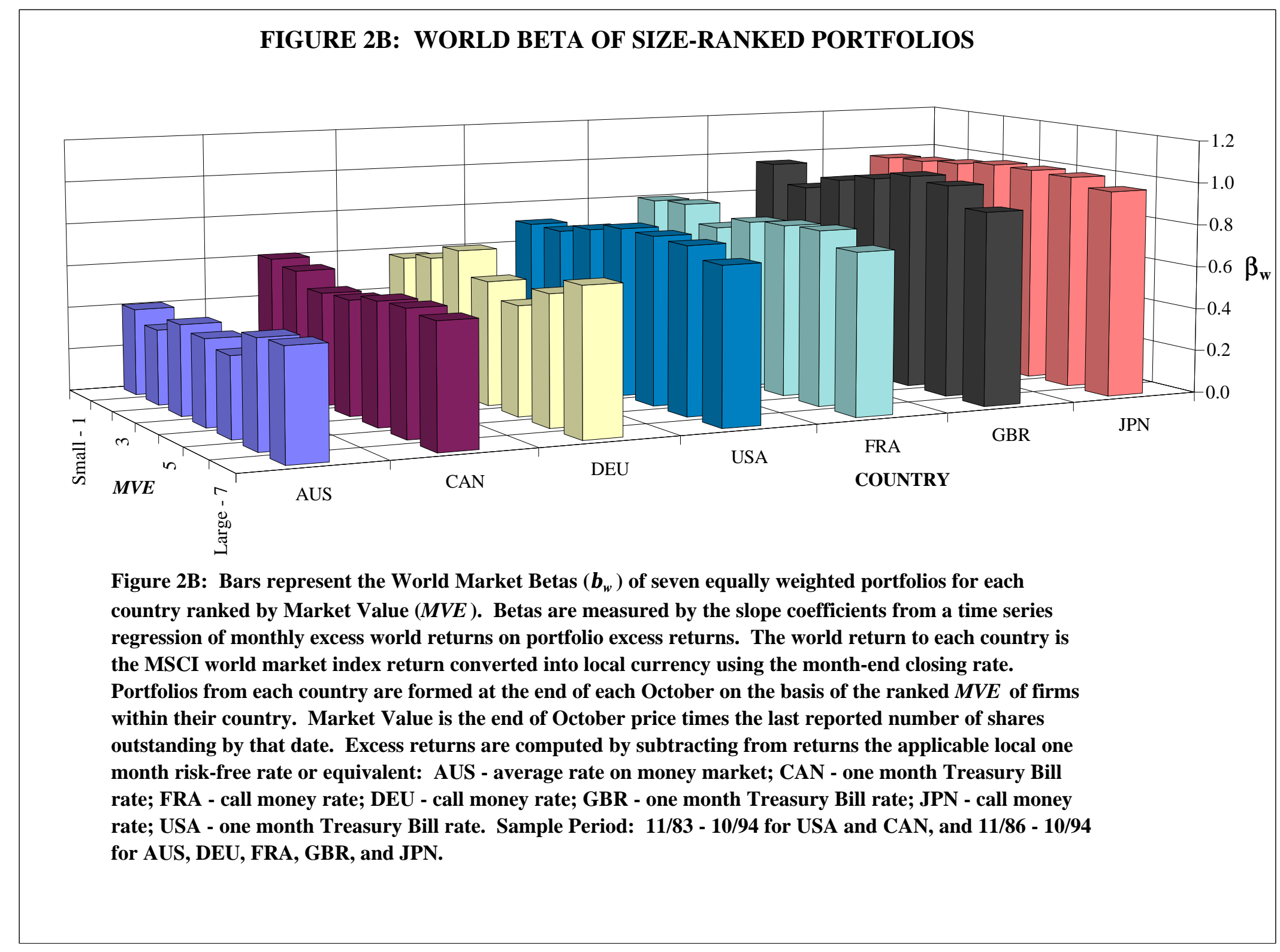




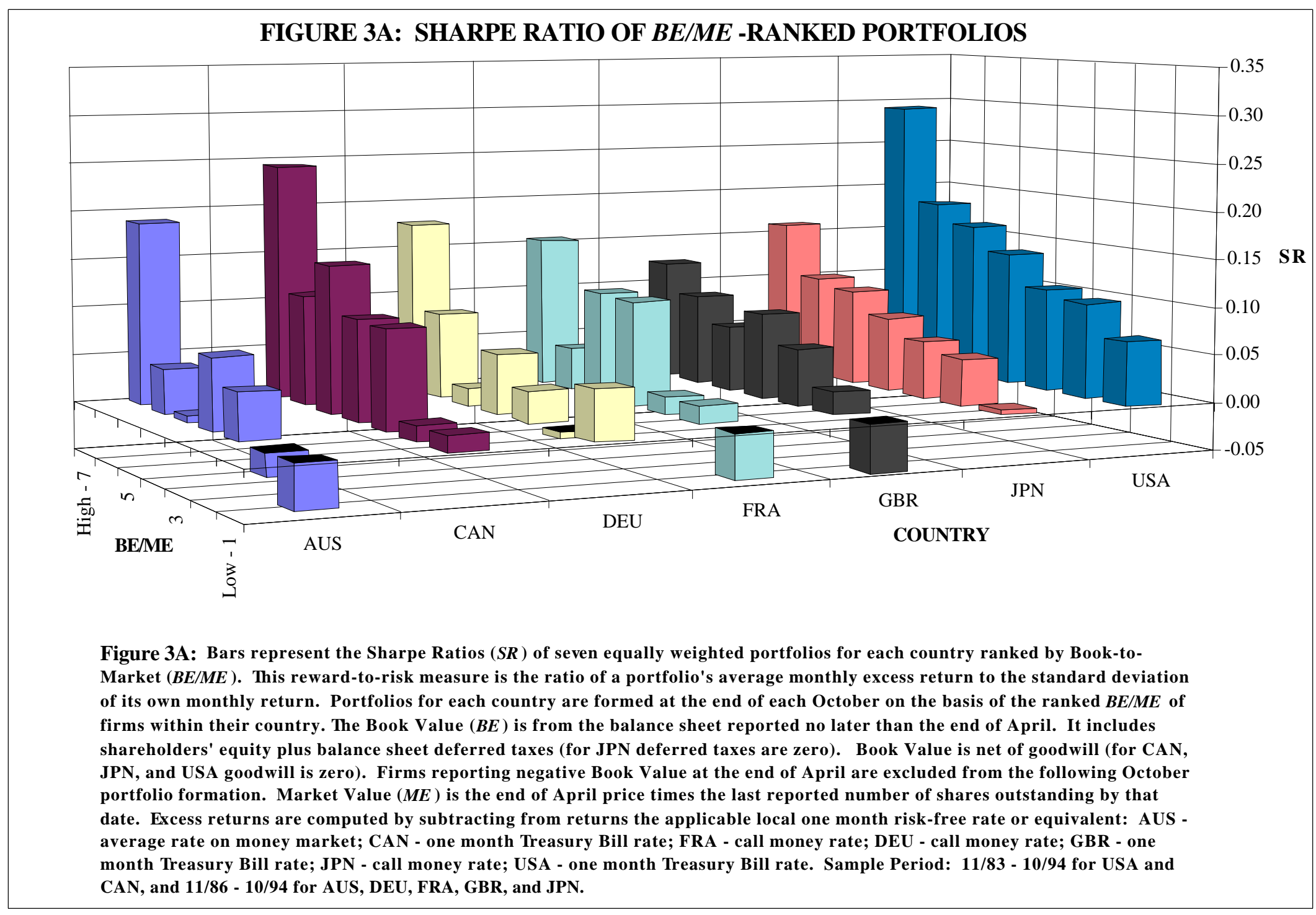


FIGURE 3B: SHARPE RATIO OF SIZE-RANKED PORTFOLIOS

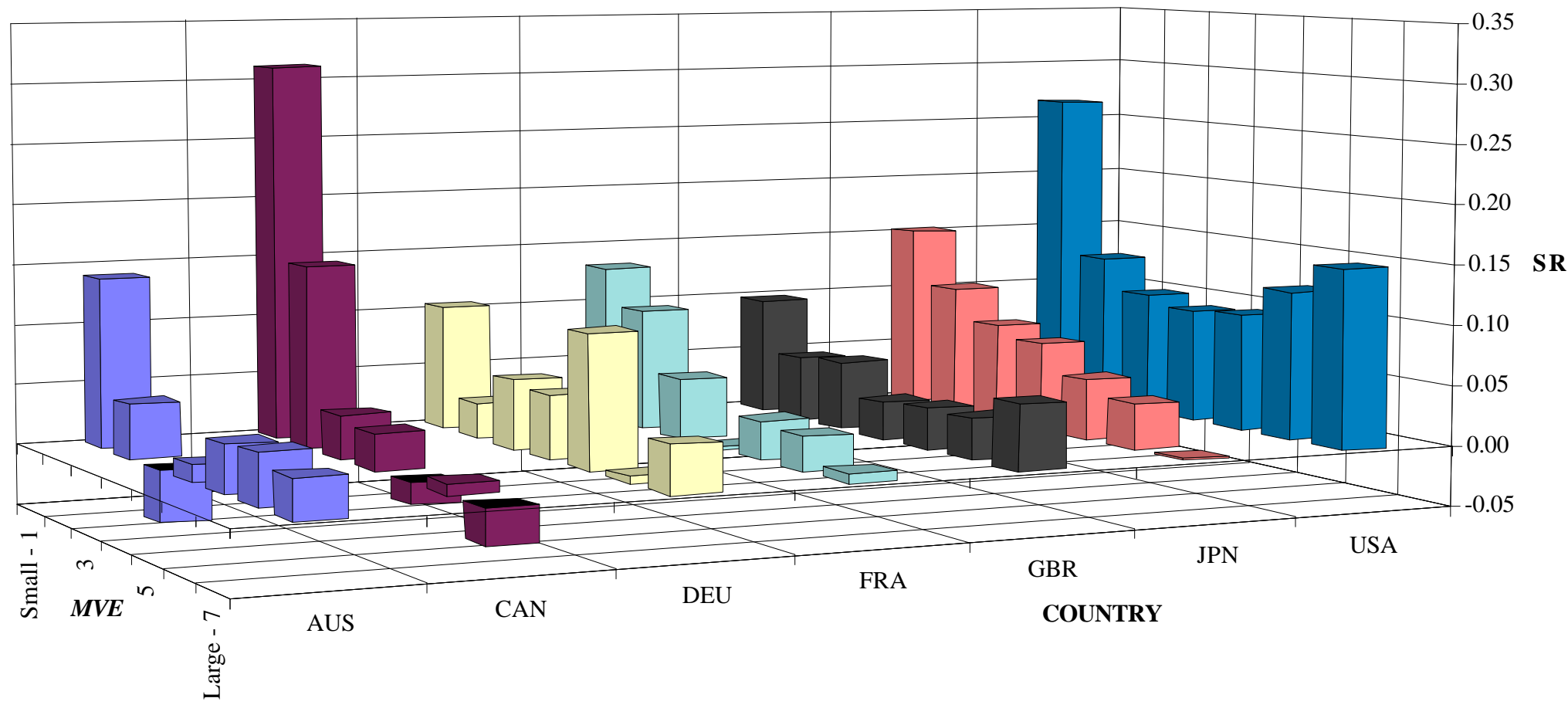

Figure 3B: Bars represent the Sharpe Ratios (SR ) of seven equally weighted portfolios for each country ranked by Market Value $(M V E)$. This reward-to-risk measure is the ratio of a portfolio's average monthly excess return to the standard deviation of its own monthly return. Portfolios from each country are formed at the end of each October on the basis of the ranked MVE of firms within their country. Market Value is the end of October price times the last reported number of shares outstanding by that date. Excess returns are computed by subtracting from returns the applicable local one month risk-free rate or equi valent: AUS - average rate on money market; CAN - one month Treasury Bill rate; FRA - call money rate; DEU call money rate; GBR - one month Treasury Bill rate; JPN - call money rate; USA - one month Treasury Bill rate. Sample Period: 11/83 - 10/94 for USA and CAN, and 11/86 - 10/94 for AUS, DEU, FRA, GBR, and JPN. 


\section{APPENDIX A}

\section{Table A-1. Jensen-Like Alpha Portfolio Performance.}

The panels below contain "Jensen-like" alpha estimates and Wald tests of joint significance for within-country groups of equally weighted portfolios comprised of firms sorted by Book-to-Market Equity $(B E / M E)$ in Panel 1, firms sorted by Market Equity $(M V E)$ in Panel 2, and firms sorted first by Market Value $(M V E)$ and then by Book-to-Market Value $(B E / M E)$ in Panels 3A-3C. There are (7) categories for one-way sortings and (3x3) categories for two-way sortings. Portfolios are re-formed at the end of each October. Market Value $(M V E)$ is the end of October price times the last reported number of shares outstanding by that date. For $B E / M E$, Market Value $(M V E)$ is measured at the end of April. The Book Value $(B E)$ is from the balance sheet reported no later than the end of April. It includes shareholders' equity plus balance sheet deferred taxes (for JPN deferred taxes are zero). Book Value is net of goodwill (for CAN, JPN, and USA goodwill is zero). Firms reporting negative Book Value at the end of April are excluded from the following October portfolio formation.

The Jensen-like alphas are from the following modified zero-beta CAPM SURE system estimated separately for each one- and two-way portfolio sorting in each country: $R_{i, t}^{x}=\alpha_{0}+\alpha_{i}+\beta_{m, t} R_{m, t}^{x}+\beta_{w, i} R_{w, t}^{x}+\varepsilon_{i, t}$, where $R_{i, t}^{x}, R_{m, t}^{x}$, and $R_{w, t}^{x}$ are respectively excess monthly returns for the $i^{\text {th }}$ portfolio, the MSCI local market, and the MSCI world portfolio; this last is translated into local currency using the month-end exchange rate. All returns are annualized and expressed in excess of the local risk-free rate or equivalent: AUS - average rate on money market; CAN - one month Treasury Bill rate; FRA - call money rate; DEU - call money rate; GBR - one month Treasury Bill rate; JPN - call money rate; USA - one month Treasury Bill rate.

The $\alpha_{0}$ intercept term is the return on the zero-beta portfolio in excess of the risk-free rate. The $\alpha_{i}$ coefficient is the Jensen-like alpha, which is the risk adjusted return to the $i^{\text {th }}$ portfolio in excess of the zero-beta return. To identify the system, it is necessary to choose a portfolio as a reference asset (i.e., $\alpha_{l}=0$ ). The reference assets we chose are: Panel 1, the lowest $B E / M E$ sorted portfolio; Panel 2, the largest $M V E$-sorted portfolio; and Panel 3, the portfolio with the lowest $B E / M E$ and largest $M V E$ rank.

The Wald tests shown in Panels 1-3 test the hypothesis that the market model correctly prices all $B E / M E-, M V E-$, and two way-sorted portfolios (i.e., all Jensen-like alphas by country are zero). Panel 3 also depicts the joint significance by country of the Jensen-like alphas for the $B E / M E$ ranks given each $M V E$ rank. The test statistic is distributed chi-square with degrees of freedom equal to the number of restrictions.

Sample Period: 11/83 - 10/94 for USA and CAN (T=132), and 11/86 - 10/94 for AUS, DEU, FRA, GBR, and JPN $(\mathrm{T}=96)$. White-corrected standard errors are used to compute the $\mathrm{p}$-values that are in parentheses.

\section{Panel 1. Portfolios Sorted by $B E / M E\left(\alpha_{J, i}\right)$}

\begin{tabular}{|c|c|ccccccc|c|}
\hline Country & $\boldsymbol{\alpha}_{0}$ & $\begin{array}{c}\text { 1-Low } \\
\boldsymbol{B E} / \boldsymbol{M E}\end{array}$ & $\mathbf{2}$ & $\mathbf{3}$ & $\mathbf{4}$ & $\mathbf{5}$ & $\mathbf{6}$ & $\begin{array}{c}\text { 7-High } \\
\boldsymbol{B E} / \boldsymbol{M E}\end{array}$ & $\begin{array}{c}\text { All } \boldsymbol{\alpha}_{\mathrm{J}, \mathrm{i}}=\mathbf{0} \\
\text { Wald } \boldsymbol{\chi}^{\mathbf{2}}(\mathbf{6})\end{array}$ \\
\hline \hline AUS & -0.083 & Ref $=0$ & 0.031 & 0.109 & 0.106 & 0.069 & 0.105 & 0.236 & 17.033 \\
& $(.097)$ & & $(.524)$ & $(.068)$ & $(.056)$ & $(.226)$ & $(.089)$ & $(.001)$ & $(.009)$ \\
CAN & 0.004 & 0 & 0.003 & 0.041 & 0.052 & 0.073 & 0.052 & 0.186 & 20.133 \\
& $(.935)$ & & $(.951)$ & $(.331)$ & $(.223)$ & $(.075)$ & $(.237)$ & $(.002)$ & $(.003)$ \\
DEU & 0.031 & 0 & -0.044 & -0.007 & 0.015 & -0.018 & 0.035 & 0.096 & 10.547 \\
& $(.344)$ & & $(.164)$ & $(.825)$ & $(.615)$ & $(.606)$ & $(.249)$ & $(.042)$ & $(.103)$ \\
FRA & -0.041 & 0 & 0.047 & 0.050 & 0.118 & 0.128 & 0.078 & 0.172 & 20.415 \\
& $(.162)$ & & $(.195)$ & $(.109)$ & $(.001)$ & $(.001)$ & $(.059)$ & $(.000)$ & $. .002)$ \\
GBR & -0.077 & 0 & 0.057 & 0.089 & 0.103 & 0.089 & 0.108 & 0.137 & 37.828 \\
& $(.025)$ & & $(.001)$ & $(.000)$ & $(.000)$ & $(.000)$ & $(.000)$ & $(.000)$ & $(.000)$ \\
JPN & 0.006 & 0 & 0.045 & 0.052 & 0.069 & 0.083 & 0.091 & 0.136 & 15.518 \\
& $(.918)$ & & $(.015)$ & $(.014)$ & $(.002)$ & $(.001)$ & $(.001)$ & $(.000)$ & $(.017)$ \\
USA & -0.039 & 0 & 0.019 & 0.024 & 0.054 & 0.065 & 0.071 & 0.144 & 45.428 \\
& $(.279)$ & & $(.249)$ & $(.182)$ & $(.010)$ & $(.006)$ & $(.003)$ & $(.000)$ & $(.000)$ \\
\hline
\end{tabular}


Panel 2. Portfolios Sorted by $M V E\left(\alpha_{j, i}\right)$

\begin{tabular}{|c|c|c|c|c|c|c|c|c|c|}
\hline Country & $\alpha_{0}$ & $\begin{array}{c}\text { 1-Small } \\
M V E\end{array}$ & 2 & 3 & 4 & 5 & 6 & $\begin{array}{c}\text { 7-Large } \\
M V E\end{array}$ & $\begin{array}{c}\text { All } \alpha_{\mathrm{J}, \mathrm{i}}=0 \\
\text { Wald } \chi^{2}(6)\end{array}$ \\
\hline AUS & $\begin{array}{c}-0.005 \\
(.764)\end{array}$ & $\begin{array}{l}0.128 \\
(.161)\end{array}$ & $\begin{array}{l}0.022 \\
(.628)\end{array}$ & $\begin{array}{c}-0.045 \\
(.350)\end{array}$ & $\begin{array}{l}0.005 \\
(.905)\end{array}$ & $\begin{array}{l}0.006 \\
(.879)\end{array}$ & $\begin{array}{l}0.013 \\
(.721)\end{array}$ & $\operatorname{Ref}=0$ & $\begin{array}{l}4.762 \\
(.575)\end{array}$ \\
\hline CAN & $\begin{array}{c}-0.027 \\
(.042)\end{array}$ & $\begin{array}{l}0.362 \\
(.000)\end{array}$ & $\begin{array}{l}0.115 \\
(.000)\end{array}$ & $\begin{array}{l}0.046 \\
(.089)\end{array}$ & $\begin{array}{l}0.034 \\
(.136)\end{array}$ & $\begin{array}{l}0.008 \\
(.713)\end{array}$ & $\begin{array}{l}0.027 \\
(.119)\end{array}$ & 0 & $\begin{array}{c}31.421 \\
(.000)\end{array}$ \\
\hline DEU & $\begin{array}{l}0.021 \\
(.334)\end{array}$ & $\begin{array}{l}0.048 \\
(.409)\end{array}$ & $\begin{array}{l}0.002 \\
(.977)\end{array}$ & $\begin{array}{l}0.014 \\
(.767)\end{array}$ & $\begin{array}{l}0.011 \\
(.797)\end{array}$ & $\begin{array}{l}0.060 \\
(.126)\end{array}$ & $\begin{array}{r}-0.017 \\
(.638)\end{array}$ & 0 & $\begin{array}{l}7.539 \\
(.274)\end{array}$ \\
\hline FRA & $\begin{array}{c}-0.001 \\
(.965)\end{array}$ & $\begin{array}{l}0.140 \\
(.048)\end{array}$ & $\begin{array}{l}0.072 \\
(.106)\end{array}$ & $\begin{array}{l}0.034 \\
(.359)\end{array}$ & $\begin{array}{r}-0.001 \\
(.974)\end{array}$ & $\begin{array}{l}0.018 \\
(.602)\end{array}$ & $\begin{array}{l}0.019 \\
(.548)\end{array}$ & 0 & $\begin{array}{l}7.455 \\
(.281)\end{array}$ \\
\hline GBR & $\begin{array}{c}-0.005 \\
(.688)\end{array}$ & $\begin{array}{l}0.054 \\
(.336)\end{array}$ & $\begin{array}{l}0.024 \\
(.605)\end{array}$ & $\begin{array}{l}0.015 \\
(.717)\end{array}$ & $\begin{array}{c}-0.008 \\
(.822)\end{array}$ & $\begin{array}{c}-0.004 \\
(.877)\end{array}$ & $\begin{array}{c}-0.014 \\
(.461)\end{array}$ & 0 & $\begin{array}{l}5.419 \\
(.491)\end{array}$ \\
\hline JPN & $\begin{array}{l}0.002 \\
(.924)\end{array}$ & $\begin{array}{l}0.159 \\
(.025)\end{array}$ & $\begin{array}{l}0.105 \\
(.068)\end{array}$ & $\begin{array}{l}0.079 \\
(.136)\end{array}$ & $\begin{array}{l}0.071 \\
(.135)\end{array}$ & $\begin{array}{l}0.052 \\
(.168)\end{array}$ & $\begin{array}{l}0.033 \\
(.205)\end{array}$ & 0 & $\begin{array}{l}9.218 \\
(.162)\end{array}$ \\
\hline USA & $\begin{array}{c}-0.008 \\
(.290)\end{array}$ & $\begin{array}{l}0.325 \\
(.001)\end{array}$ & $\begin{array}{l}0.031 \\
(.444)\end{array}$ & $\begin{array}{l}0.003 \\
(.911)\end{array}$ & $\begin{array}{r}-0.010 \\
(.727)\end{array}$ & $\begin{array}{c}-0.014 \\
(.556)\end{array}$ & $\begin{array}{r}-0.009 \\
(.522)\end{array}$ & 0 & $\begin{array}{c}14.063 \\
(.029)\end{array}$ \\
\hline
\end{tabular}

Panel 3A. Portfolios Sorted by $M V E$ then by $B E / M E$ :

Small-Cap MVE $\left(\alpha_{J, i}\right)$.

\begin{tabular}{|c|c|c|c|c|c|c|}
\hline Country & $\alpha_{0}$ & $\begin{array}{l}\text { All } \alpha_{\mathrm{J}, \mathrm{i}}=0 \\
\text { Wald } \chi^{2}(8)\end{array}$ & $\begin{array}{c}\text { 1-Low } \\
B E / M E\end{array}$ & 2 & $\begin{array}{l}\text { 3-High } \\
B E / M E\end{array}$ & $\begin{array}{l}\alpha_{\mathrm{J}, 2}-\alpha_{\mathrm{J}, 1}=\mathbf{0} \\
\alpha_{\mathrm{J}, 3}-\alpha_{\mathrm{J}, 1}=\mathbf{0} \\
\text { Wald } \chi^{2}(2)\end{array}$ \\
\hline AUS & $\begin{array}{l}-0.017 \\
(.601)\end{array}$ & $\begin{array}{c}19.389 \\
(.013)\end{array}$ & $\begin{array}{l}0.007 \\
(.920)\end{array}$ & $\begin{array}{c}-0.013 \\
(.846)\end{array}$ & $\begin{array}{l}0.203 \\
(.009)\end{array}$ & $\begin{array}{c}13.925 \\
(.001)\end{array}$ \\
\hline CAN & $\begin{array}{r}-0.026 \\
(.272)\end{array}$ & $\begin{array}{c}61.976 \\
(.000)\end{array}$ & $\begin{array}{l}0.176 \\
(.002)\end{array}$ & $\begin{array}{l}0.189 \\
(.000)\end{array}$ & $\begin{array}{l}0.289 \\
(.000)\end{array}$ & $\begin{array}{l}2.431 \\
(.297)\end{array}$ \\
\hline DEU & $\begin{array}{l}0.005 \\
(.899)\end{array}$ & $\begin{array}{l}9.538 \\
(.299)\end{array}$ & $\begin{array}{l}0.018 \\
(.671)\end{array}$ & $\begin{array}{l}0.019 \\
(.651)\end{array}$ & $\begin{array}{l}0.117 \\
(.071)\end{array}$ & $\begin{array}{l}2.976 \\
(.226)\end{array}$ \\
\hline FRA & $\begin{array}{l}0.014 \\
(.603)\end{array}$ & $\begin{array}{c}19.924 \\
(.011)\end{array}$ & $\begin{array}{l}0.038 \\
(.455)\end{array}$ & $\begin{array}{l}0.057 \\
(.285)\end{array}$ & $\begin{array}{l}0.187 \\
(.001)\end{array}$ & $\begin{array}{l}8.809 \\
(.012)\end{array}$ \\
\hline GBR & $\begin{array}{r}-0.042 \\
(.047)\end{array}$ & $\begin{array}{c}39.653 \\
(.000)\end{array}$ & $\begin{array}{l}0.030 \\
(.517)\end{array}$ & $\begin{array}{l}0.067 \\
(.170)\end{array}$ & $\begin{array}{l}0.135 \\
(.003)\end{array}$ & $\begin{array}{c}14.834 \\
(.001)\end{array}$ \\
\hline JPN & $\begin{array}{r}-0.025 \\
(.515)\end{array}$ & $\begin{array}{c}23.732 \\
(.003)\end{array}$ & $\begin{array}{l}0.136 \\
(.014)\end{array}$ & $\begin{array}{l}0.157 \\
(.003)\end{array}$ & $\begin{array}{l}0.178 \\
(.001)\end{array}$ & $\begin{array}{l}2.116 \\
(.347)\end{array}$ \\
\hline USA & $\begin{array}{c}-0.040 \\
(.061)\end{array}$ & $\begin{array}{c}48.728 \\
(.000)\end{array}$ & $\begin{array}{l}0.074 \\
(.110)\end{array}$ & $\begin{array}{l}0.104 \\
(.027)\end{array}$ & $\begin{array}{l}0.154 \\
(.000)\end{array}$ & $\begin{array}{c}12.735 \\
(.002)\end{array}$ \\
\hline
\end{tabular}


Panel 3B. Portfolios Sorted by $M V E$ then by $B E / M E$ :

Mid-Cap $M V E\left(\alpha_{s, i}\right)$.

\begin{tabular}{|c|ccc|c|}
\hline Country & $\begin{array}{c}\text { 1-Low } \\
\boldsymbol{B E} / \boldsymbol{M E}\end{array}$ & $\mathbf{2}$ & $\begin{array}{c}\text { 3-High } \\
\boldsymbol{B E} / \boldsymbol{M E}\end{array}$ & $\begin{array}{c}\boldsymbol{\alpha}_{\mathrm{J}, 2}-\boldsymbol{\alpha}_{\mathrm{J}, 1}=\mathbf{0} \\
\boldsymbol{\alpha}_{\mathrm{J}, 3}-\boldsymbol{\alpha}_{\mathrm{J}, 1}=\mathbf{0} \\
\text { Wald } \boldsymbol{\chi}^{\mathbf{2}}(\mathbf{2})\end{array}$ \\
\hline \hline AUS & -0.093 & 0.039 & 0.037 & 5.122 \\
& $(.144)$ & $(.377)$ & $(.510)$ & $(.077)$ \\
CAN & -0.045 & 0.064 & 0.089 & 25.708 \\
& $(.126)$ & $(.013)$ & $(.003)$ & $(.000)$ \\
DEU & -0.001 & 0.029 & 0.070 & 2.932 \\
& $(.971)$ & $(.511)$ & $(.111)$ & $(.231)$ \\
FRA & -0.059 & 0.022 & 0.028 & 6.411 \\
& $(.161)$ & $(.577)$ & $(.561)$ & $(.041)$ \\
GBR & -0.003 & 0.058 & 0.042 & 9.857 \\
& $(.919)$ & $(.087)$ & $(.121)$ & $(.007)$ \\
JPN & 0.043 & 0.089 & 0.138 & 11.578 \\
& $(.182)$ & $(.015)$ & $(.001)$ & $(.003)$ \\
USA & -0.020 & 0.039 & 0.064 & 16.167 \\
& $(.383)$ & $(.124)$ & $(.012)$ & $(.000)$ \\
\hline
\end{tabular}

Panel 3C. Portfolios Sorted by $M V E$ then by $B E / M E$ :

Large-Cap $M V E\left(\alpha_{J_{i}}\right)$.

\begin{tabular}{|c|ccc|c|}
\hline Country & $\begin{array}{c}\text { 1-Low } \\
\boldsymbol{B E} / \boldsymbol{M E}\end{array}$ & $\mathbf{2}$ & $\begin{array}{c}\text { 3-High } \\
\boldsymbol{B E} / \boldsymbol{M E}\end{array}$ & $\begin{array}{c}\boldsymbol{\alpha}_{\mathrm{J}, 2}=\mathbf{0} \\
\boldsymbol{\alpha}_{\mathrm{J}, 3}=\mathbf{0} \\
\text { Wald } \boldsymbol{\chi}^{\mathbf{2}}(\mathbf{2})\end{array}$ \\
\hline \hline AUS & Ref=0 & 0.022 & 0.053 & 1.003 \\
& & $(.531)$ & $(.327)$ & $(.606)$ \\
CAN & 0 & 0.018 & 0.029 & 1.243 \\
& & $(.465)$ & $(.268)$ & $(.537)$ \\
DEU & 0 & 0.017 & 0.062 & 2.702 \\
& & $(.704)$ & $(.203)$ & $(.259)$ \\
FRA & 0 & 0.003 & -0.013 & 0.207 \\
& & $(.924)$ & $(.724)$ & $(.902)$ \\
GBR & 0 & 0.045 & 0.065 & 10.901 \\
& & $(.006)$ & $(.005)$ & $(.004)$ \\
JPN & 0 & 0.058 & 0.091 & 9.486 \\
& & $(.003)$ & $(.006)$ & $(.009)$ \\
USA & 0 & 0.032 & 0.052 & 4.370 \\
& & $(.078)$ & $(.042)$ & $(.112)$ \\
\hline
\end{tabular}




\section{APPENDIX B}

\section{STOCHASTIC DISCOUNT FACTORS}

Hansen \& Jagannathan (HJ, 1991) derive restrictions from the Law of One Price (LOP) that must apply to any stochastic discount factor (SDF) that can price a set of assets. The LOP articulates a minimal requirement for market efficiency, that assets with the same payoff structure sell for the same price. HJ show how to derive a lower bound on the volatility of SDFs that will price any specified set of assets. These SDFs capture all the information available from linear combinations of asset returns to price average returns exactly. ${ }^{41}$ There is a single minimumvariance SDF that will price any set of assets for each possible riskless rate, $r_{f}$. Unconditional and conditional versions of these SDFs can be used to construct "spanning" tests that do not depend on any specific asset pricing model or distributional assumptions. Below we discuss the construction and some important properties of SDFs.

The basic requirement of an asset pricing model is that prices correctly reflect expected discounted payoffs. Stated formally,

$$
E\left[\mathbf{X}_{t+1} m_{t+1}\right]=P_{t}, \quad \text { or } \quad(\text { B } 1 \mathrm{~b}) \quad E\left[\mathrm{R}_{t+1} m_{t+1}\right]=1_{n} .
$$

Here $\mathrm{X}_{t+1}$ and $\mathrm{R}_{t+1}$ are $n \times \omega$ matrices of payoffs and returns of the $n$ assets in each of $\omega$ possible states at date $t+1, P_{t}$ is the $n \times 1$ vector of the corresponding prices at date $t, m_{t+t}$ is the $\omega \times 1$ vector of the SDF, and $1_{\mathrm{n}}$ is the $n \times 1$ unity vector. The Law of One Price (LOP), gives the weakest conditions on $m{ }^{42}$ it merely requires that $m$ exist. ${ }^{43}$ This requirement is met if the second moment matrix of payoffs $E[R R]$ is of full rank.

Under the assumption that the asset returns distributions are ergodic, one can treat every observation as a realization of a state $\omega$. This makes it possible to use time series data of returns to evaluate the expectations in (1b) and to calculate the SDF (Hansen \& Richard, 1987). To compute the SDF, $m_{c}$, expand equation (1b) to get,

$$
E\left[\mathrm{R} m_{c}\right]=E[\mathrm{R}] E\left[m_{c}\right]+\operatorname{Cov}\left[\mathrm{R} m_{c}\right]=1_{n} \text {, or } E[\mathrm{R}]=\frac{1_{n}-\operatorname{Cov}\left[\mathrm{R} m_{c}\right]}{E\left[m_{c}\right]} .
$$

41 The SDF is closely related to state prices; its existence does not depend on market completeness.

42 Various asset pricing models can be derived by placing alternative restrictions on the discount factor $m$. For example, the no-arbitrage restriction implies a positive discount factor, $m>0$ (no negative prices on assets with non-negative payoffs). Expected utility models interpret $m$ as the intertemporal marginal rate of substitution (IMRS), which requires $m$ to be positive, and to be related to consumption through some utility function. HJ (1991) provide a method to guarantee $m>0$. Stutzer (1993) also provides a functional form that guarantees $m>0$ consistent with CRRA utility.

43 This requirement rules out profits from re-packaging assets, and it results in prices that are linear in their payoffs, because payoffs are independent of the initial investment. See Ingersoll (1987) and Ross (1976). 
where $m$ is now a $T x 1$ random variable $m_{c}$, and $\mathrm{R}$ is a $n \times T$ matrix of $T$ observations on $n$ assets. The expected SDF, $E\left[m_{c}\right]=c=1 / r_{f}$, is the price of a riskless asset. ${ }^{44}$ Expanding the covariance and substituting in (2) gives,

$$
E\left[(\mathrm{R}-E(\mathrm{R}))\left(m_{c}-c\right)\right]=1_{n}-E(\mathrm{R}) c,
$$

where the SDF is a linear function of returns, and,

$$
m_{c}=[\mathrm{R}-E(\mathrm{R})]^{\prime} \beta_{c}+c,
$$

where $\beta_{c}$ is an $n \times 1$ vector of weights for each asset. The solution of equation (3) is given by, $\beta_{c}=\Sigma^{-1}\left[1_{n}-E(\mathrm{R}) c\right]$, where $\Sigma$ is the covariance matrix of gross returns. The SDF, $m_{c}$,

replicates exactly the sample averages of the included asset returns for any specific risk free rate, $r_{f}$. The SDFs over all possible risk-free rates, $r_{f}$, form the lower bound on the volatility of all possible discount factors. ${ }^{45}$

44 The definition of a risk free asset is that it has a unit payoff regardless of the state of the world. Substituting a unit payoff vector for the payoff matrix $(\mathbf{X})$ into equation (1a) and taking expectations $\mathrm{E}\left[1 m_{c}\right]=p_{c}=\mathrm{E}\left[m_{c}\right]=p_{c}=c$, and $1 / \mathrm{E}[m]=1 / p_{c}=r_{f}$.

45 The variance of $m_{c}$ is given by, $\sigma^{2}\left(m_{c}\right)=\beta_{c}{ }^{2} \Sigma \beta_{c}=\operatorname{Co}[\mathrm{R} m] \beta_{c}$. The minimum variance property of this SDF, and its construction from the first two moments of returns data, gives a duality between the Hansen and Jagannathan bound and the Markowitz mean variance frontier. The duality between the volatility bound and the mean variance frontier can be easily illustrated by noticing that the portfolio that composes $m_{c}$ will have the maximal Sharpe Ratio (i.e., be tangent to the mean variance frontier with intercept equal to the risk free rate) of any candidate SDF (HJ, 1991; De Santis, 1993; Stutzer, 1993). 


\section{APPENDIX C}

\section{ILLUSTRATION OF THE GMM ESTIMATION METHODOLOGY}

The parameters of the HJ model are estimated with Hansen's (1982) Generalized Method of Moments (GMM). The GMM objective is to find a set of parameters that obey a set of sample orthogonality conditions as closely as possible. The model we label unconditional spanning in equations $(3 \mathrm{a}, \mathrm{b})$ with conditioning information is used here for illustration. First, form the vector of sample moments from the orthogonality conditions in equation (10a): ${ }^{46}$

$E\left(\varepsilon_{t}\right)=E\left(\varepsilon_{t} \oplus Z_{i,-l}\right)=0$ give,

$$
h_{T}\left(b_{p, 1}, b_{p, 2}, g_{p, 1}, g_{p, 2}\right)=\frac{1}{T} \sum_{t=1}^{T}\left[\begin{array}{l}
\varepsilon_{t} \otimes 1 \\
\varepsilon_{t} \oplus Z_{s, t-1}
\end{array}\right],
$$

where $h_{T}$ is a $2(n+w)$ vector of sample moments (i.e., of time-series averages) that dependent on the estimates $b_{p, 1}, b_{p, 2}, g_{p, l}$ and $g_{p, 2}$ of the SDF population parameters $\beta_{p, l}, \beta_{p, 2}, \theta_{p, l}$, and $\theta_{p, 2}$. The objective is to find a set of parameters that minimize a generic least square quadratic form of sample moments,

$$
\min _{b_{p, 1}, b_{p, 2}, g_{p, 1}, g_{p, 2}}=h_{T}\left(b_{p, 1}, b_{p, 2}, g_{p, 1}, g_{p, 2}\right)^{\prime} \mathbf{w}_{T} h_{T}\left(b_{p, 1}, b_{p, 2}, g_{p, 1}, g_{p, 2}\right),
$$

where $\mathbf{w}_{T}$ is a $\{2(n+w) \times 2(n+w)\}$ symmetric weighting matrix that is the inverse of a consistent estimate of the covariance matrix of orthogonality conditions. Hansen describes the form of $\mathbf{w}_{\mathrm{r}}$ that guarantees estimates to be consistent and asymptotically normal. Various choices of this weighting matrix make GMM estimates robust to autocorrelation and heteroskedasticity. ${ }^{47} \mathrm{~A}$ consistent estimate of $\mathbf{w}_{T}$ in the presence of heteroskedasticity is:

$$
\mathbf{w}_{T}=\left\{\frac{1}{T} \sum_{t=1}^{T}\left[\left(\begin{array}{ll}
\varepsilon_{t} \otimes 1 \\
\varepsilon_{t} \oplus Z_{t-1}
\end{array}\right)\left(\begin{array}{l}
\varepsilon_{t} \otimes 1 \\
\varepsilon_{t} \oplus Z_{s, t-1}
\end{array}\right)\right]\right\}^{\prime} .
$$

The minimized value of the objective function $\Gamma^{*}$ provides a test of the $2(q+w)^{48}$ overidentifying restrictions imposed by spanning in equations (6). Hansen's J Statistic, $J=T^{*} \sim \chi_{2(q+w)}^{2}$, is distributed chi-square with degrees of freedom equal to the number of overidentifying conditions. The $J$-statistic tests how well the orthogonality conditions are met in the sample.

46 The Kronecker product $\otimes$ (i.e., every element in matrix A times each element in matrix B) is usually used in the literature. We use the Hadamard product $\oplus$ (i.e., every element of a row $k$ in matrix A with every element of column $k$ of matrix $\mathbf{B}$ ) because each of our instruments is portfolio specific.

47 The form of $\mathbf{w}_{\mathrm{T}}$ without corrections is equivalent to 3SLS if there are overidentifying conditions, and GLS if there are no overidentifying conditions. Refer to Newey and West (1987) for optimal choices of $\mathbf{w}_{T}$ in the presence of autocorrelation and heteroskedasticity that also ensure this matrix is positive definite. GMM estimates of this paper are made robust to heteroskedasticity and first order autocorrelation using a Bartlett spectral density kernel to maintain positive definiteness (reviewed by Andrews [1991]).

${ }^{48}$ The number of restrictions tested is always 2 times the number of test assets $(2 q=4)$. The portfolio-specific instrument $w$ on the test assets is not tested for orthogonality with pricing errors because we seek only to test the average pricing error not the conditional average pricing error. 
Numerically, GMM estimation proceeds in stages because the objective is a complicated function of the parameters. In the first step, a set of parameters are estimated $\left(b_{p, l}, b_{p, 2}, g_{p, l}, g_{p, 2}\right.$ given an identity matrix for $\mathbf{w}_{\mathrm{T}}$. In each of the successive iterations, a new estimate of $\mathbf{w}_{\mathrm{T}}$ is computed from the parameters of the last iteration, and new parameters are estimated in turn. This process need only continue for two iterations (two-stage GMM), to obtain a consistent estimate for $\mathbf{w}_{\mathrm{T}}$. However, additional iterations or iterating until a convergence criterion is met, (iterative GMM), may improve the accuracy of small sample estimates. ${ }^{49}$

Ferson and Foerster (1994) provide Monte Carlo evidence that iterative GMM is more reliable in small samples, especially when estimating larger systems. ${ }^{50}$ They find two-stage GMM tends to reject overidentifying conditions (i.e., the model) too often, with this bias becoming more pronounced in larger systems. Iterated GMM, while more reliable, has a slight tendency to reject less frequently than it should. Surprisingly, the small sample J-statistic from a simple model with few instruments conforms well to its asymptotic distribution with as few as 60 time series observations (using either two-stage or iterative GMM). ${ }^{51}$

49 Successive approximation methods, like the one employed here, do not guarantee convergence to a fixed point. The results reported here are obtained using iterative GMM.

50 The authors use a single-latent-variables model to conduct their simulations. They caution that the results of Monte Carlo studies are usually sensitive to the model and the artificial data used. Iterative GMM is also preferable in the presence of heteroskedasticity (Arellano and Bond, 1991).

51 The smallest model had three instruments (including a constant) and two test assets (df=4). Parameter estimates and standard errors also seem unbiased. As model complexity increases, parameter estimates become unreliable and standard errors are biased downward in small samples. However, the J-statistic from iterative GMM is generally well-behaved. 